\title{
Sensing and Demodulation of Special Long-Period Fiber Gratings Induced by Scanning $\mathrm{CO}_{2}$ Laser Pulses
}

\author{
Tao Zhu, Leilei Shi, Min Liu, and Wei Huang \\ Key Laboratory of Optoelectronic Technology and Systems of the Ministry of Education of China, Chongqing University, \\ Chongqing 400044, China \\ Correspondence should be addressed to Tao Zhu, zhutao@cqu.edu.cn
}

Received 16 March 2012; Revised 28 September 2012; Accepted 8 October 2012

Academic Editor: Eugenio Martinelli

Copyright ( 2012 Tao Zhu et al. This is an open access article distributed under the Creative Commons Attribution License, which permits unrestricted use, distribution, and reproduction in any medium, provided the original work is properly cited.

A review of long-period fiber gratings (LPFGs) with special structures induced by scanning $\mathrm{CO}_{2}$ laser pulses in single mode fiber (SMF) is presented in this paper. In the first part, the special structures and fabrication methods of LPFGs are demonstrated in detail. Next, the special LPFG-based sensors are demonstrated, such as refractive index sensor, strain sensor with temperature compensation, and torsion sensor without temperature crosstalking. Finally, several investigation methods including intensity, wavelength shift, and fiber ring laser demodulation are discussed.

\section{Introduction}

Long period fiber grating (LPFG) with a typical period of tens or hundreds of micrometers could couple the fundamental core mode to the cladding modes under the phase match condition, leaving a series of notches at some specific wavelengths in the transmission spectrum [9]. LPFG is more sensitive to the ambient perturbations than fiber Bragg grating (FBG) in which modes coupling takes place only between forward and backward core modes. So far, LPFG has been used for the measurements of refractive index, temperature, bending and torsion, and so forth. Many methods have been proposed to fabricate LPFG, such as ultraviolet (UV) laser exposure [9-13], electric-arc discharge [14-19], $\mathrm{CO}_{2}$ laser irradiation [2, 20-29], mechanical pressure [3035], etched corrugations [36-39], ion beam implantation $[40,41]$, and femtosecond laser exposure [42-50]. Among them, UV laser exposure method is most popular owing to its easy fabrication, high repeatability, and mass fabrication of symmetric LPFGs. However, the requirement to the photosensitive fiber is the disadvantage of this method, leading to that the fabricated gratings cannot work over high temperature conditions (say, more than $250^{\circ} \mathrm{C}$ ). Electricarc discharge, mechanical pressure, etched corrugations, ion beam implantation, femtosecond laser exposure, and point $\mathrm{CO}_{2}$ laser or scanning $\mathrm{CO}_{2}$ laser irradiation all are asymmetric fabrication methods. Except for scanning $\mathrm{CO}_{2}$ laser method, other fabrication methods can not realize mass fabrication and high repetition grating fabrication. In particular, these methods also cannot fabricate special LPFGs with complicated index profile.

Compared with other techniques, employing scanning $\mathrm{CO}_{2}$ laser pulses to fabricate LPFG is flexible and lowcost. This is because hydrogen loading and other additional process are not required and it is convenient to fabricate LPFGs with special refractive index modulation distribution [1, 3-7, 51-57]. It is important for LPFGs to enhance sensing sensitivity and overcome the crossinfluence among measured parameters, such as refractive index, strain, torsion, and temperature. That is why some special LPFGs are proposed in recent years. In this paper a review of $\mathrm{CO}_{2}$ laser-induced special LPFGs is presented. The principle and fabrication of the special LPFGs including the LPFGs with rotary refractive index modulation, edge distributed refractive index modulation, or periodic grooves are presented in Section 2. The special LPFG-based sensors used for measuring the ambient refractive index, torsion, and strain are listed in Section 3. The investigation methods of the 


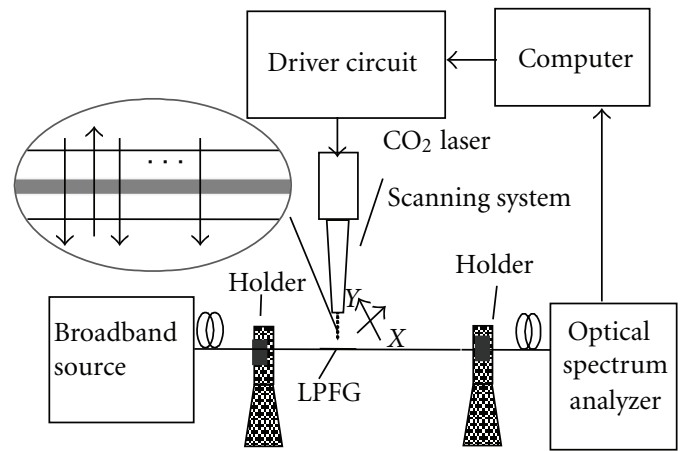

(a)

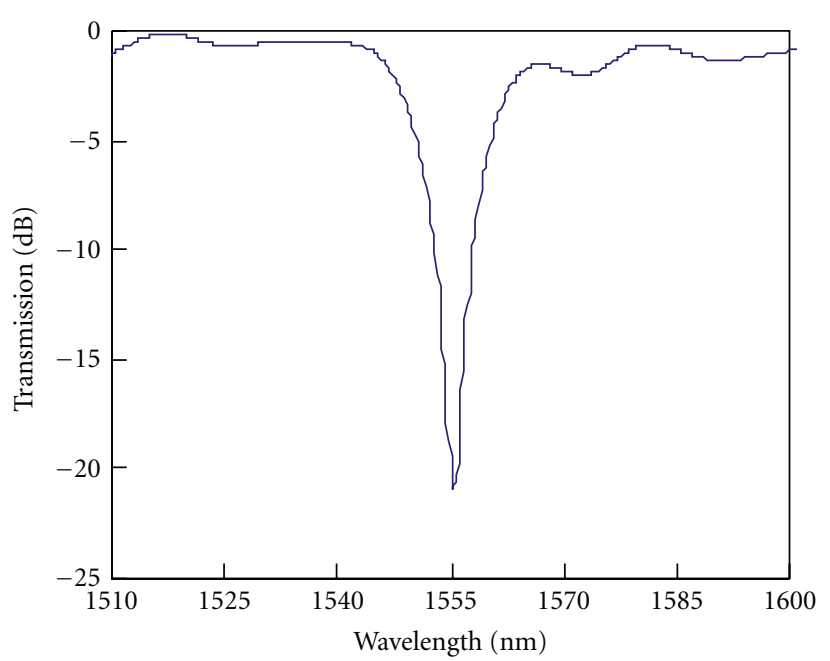

(b)

FIGURE 1: (a) Schematic diagram of the setup for fabricating the LPFGs using $\mathrm{CO}_{2}$ laser [1]. (b) Transmission spectrum of the LPFG with grating period of $630 \mu \mathrm{m}$ and grating length of $37.8 \mathrm{~mm} \mathrm{[2].}$

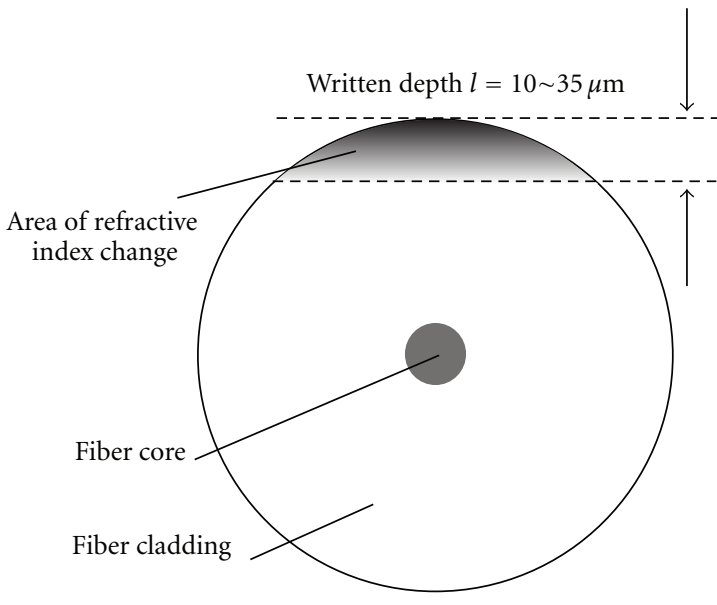

(a)

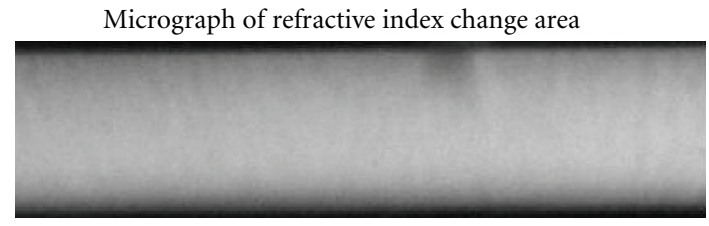

(b)

FIgUre 2: (a) Refractive index distribution of the cross section of the E-LPFG. (b) Micrograph of the E-LPFG [1].

sensors are summarized in Section 4, such as wavelength shift method, intensity and fiber ring laser demodulation method. Conclusion is in Section 5.

\section{Principle and Fabrication of $\mathrm{CO}_{2}$ Laser-Induced LPFGs}

2.1. Normal LPFGs. Figure 1(a) shows the schematic diagram of the setup for fabricating LPFGs using scanning $\mathrm{CO}_{2}$ laser. The $\mathrm{CO}_{2}$ laser beam that focuses on the fiber scans across the fiber transversely ( $X$ direction) and then advances along the fiber ( $Y$ direction) with a step equal to the grating period. The difference between point $\mathrm{CO}_{2}$ laser method and scanning $\mathrm{CO}_{2}$ method is the moving objects; that is, only the fiber is movable for the former while only the $\mathrm{CO}_{2}$ laser beam is movable for the latter. One scanning cycle is completed when the number of grating periods is reached. And the scanning cycle could be repeated as many times as needed. The typical transmission spectrum of an LPFG with a period of $630 \mu \mathrm{m}$ and grating length of $37.8 \mathrm{~mm}$ is shown in Figure 1(b). There is a loss peak in the spectrum since the fundamental core mode is coupled to the copropagating cladding modes which will leak out from the fiber. The wavelength at which the loss peak occurs is determined by the phase match condition $\beta_{\mathrm{co}}-\beta_{\mathrm{cl}}=2 \pi / \Lambda$, where $\beta_{\mathrm{co}}$ and $\beta_{\mathrm{cl}}$ are the propagation constants of the fundamental core mode and cladding mode, respectively, and $\Lambda$ is the grating period [9]. Thus the resonant wavelength of the LPFG could be given by $\lambda_{\text {res }}=\left(n_{\mathrm{co}}-n_{\mathrm{cl}}\right) \Lambda$, where $\lambda_{\text {res }}$ is the resonant wavelength, $n_{\mathrm{co}}$ and $n_{\mathrm{cl}}$ are the effective indices of the fundamental core mode and cladding mode, respectively.

It should be noted that the LPFGs fabricated by scanning $\mathrm{CO}_{2}$ laser method have asymmetric structures [2], which are 


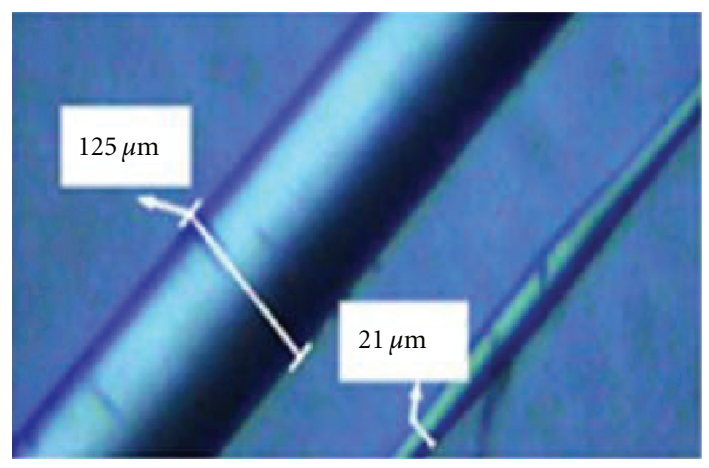

(a)

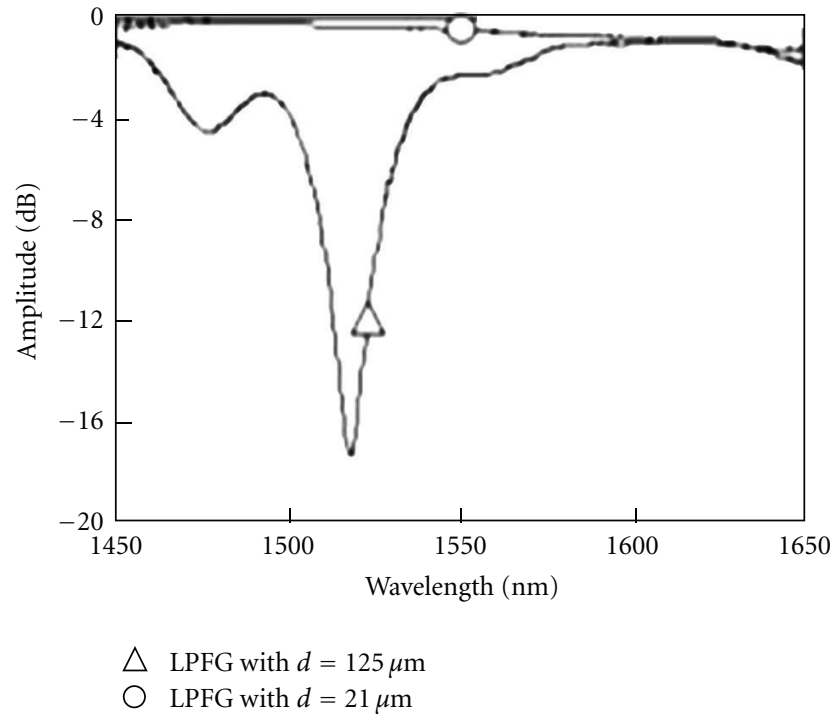

(b)

Figure 3: (a) Micrographs of the original E-LPFG and etched E-LPFG. (b) Transmission spectra of the original E-LPFG and E-LPFG with a fiber diameter of $\sim 21 \mu \mathrm{m}[1]$.

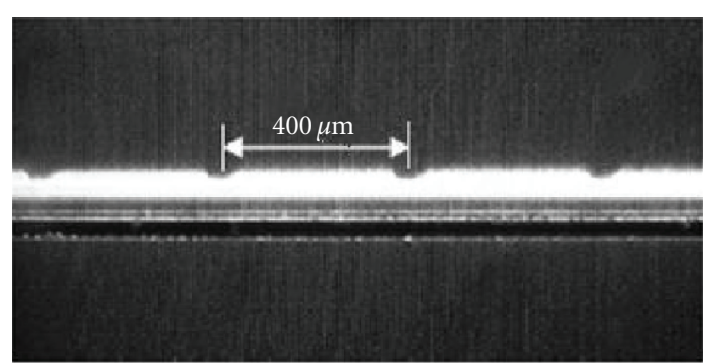

(a)

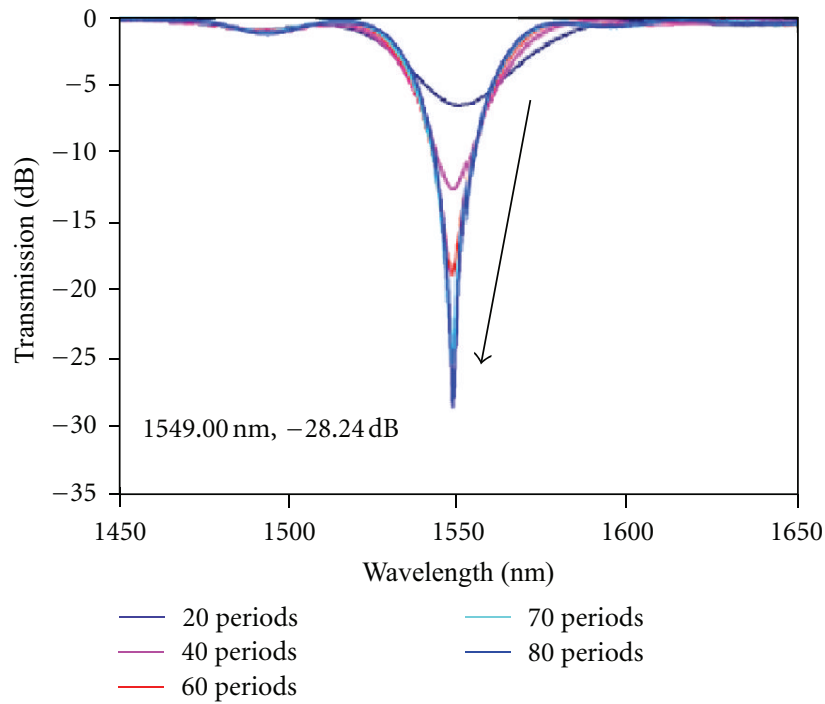

(b)

Figure 4: (a) Photograph, obtained from a charge-coupled device camera, of the $\mathrm{CO}_{2}$-laser-carved LPFG with a grating pitch of $400 \mu \mathrm{m}$. (b) Transmission spectrum evolution of the LPFG with a grating pitch of $400 \mu \mathrm{m}$ while the grating periods vary from 20 to 80 [3].

different from UV-induced LPFGs. Since the silica glass has strong absorption around the wavelength of the $\mathrm{CO}_{2}$ laser, that is, $10.6 \mu \mathrm{m}$, the beam intensity is gradually attenuated along the incident direction, resulting in asymmetric refractive index modulation within the cross section of the fiber.

\subsection{LPFGs with Special Structures}

2.2.1. Edge-Written LPFG. The refractive index modulation distributes both in the core and cladding in the $\mathrm{CO}_{2}$ laserinduced normal LPFGs. To make sure that the refractive index disturbance occurs only in the cladding region, a kind of edge-written LPFG (E-LPFG) is fabricated by properly controlling the exposure energy and pulse time of the $\mathrm{CO}_{2}$ laser using the setup shown in Figure 1(a) [1]. The refractive index distribution of the cross section of the E-LPFG is shown in Figure 2(a). The micrograph of the E-LPFG is shown in Figure 2(b), with the written depth of the LPFG $\sim 35 \mu \mathrm{m}$.

To verify that the refractive index modulation occurs only in outer cladding of the fiber, the diameter of a fiber is etched by $\sim 104 \mu \mathrm{m}$, which means that the diameter of the 


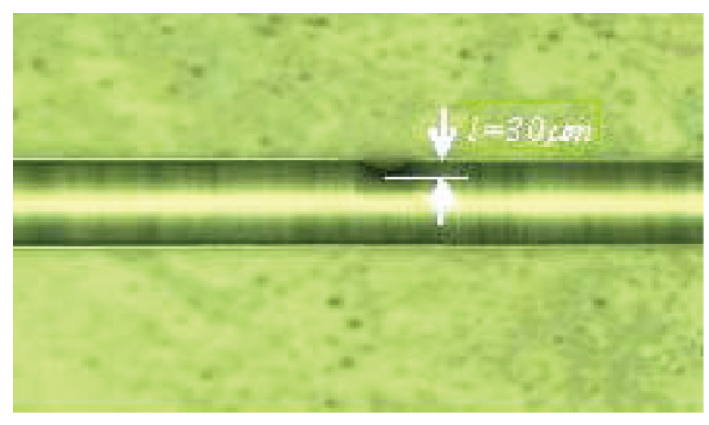

(a)

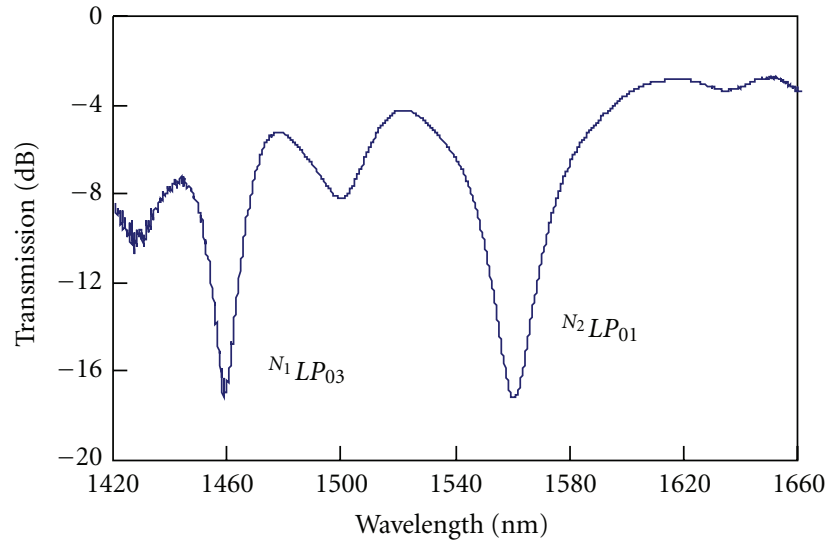

(b)

FIgUre 5: (a) Micrograph of the G-ULPFG. (b) Transmission spectrum of the G-ULPFG [4].

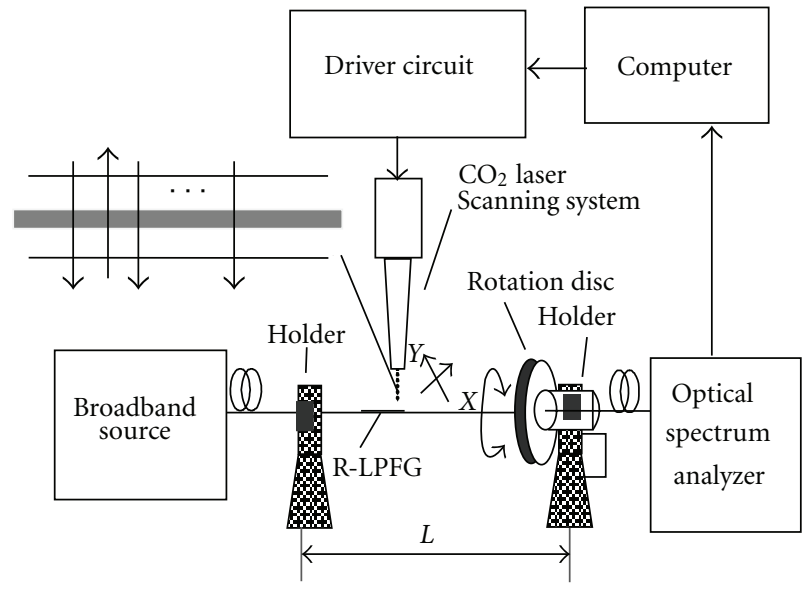

FIgURE 6: Setup for fabricating R-LPFG [5].

fiber is $\sim 21 \mu \mathrm{m}$. The partial micrographs of the original ELPFG and the etched E-LPFG are shown in Figure 3(a). The transmission spectra are shown in Figure 3(b), indicating that no grating existed when the diameter of the fiber is $\sim 21 \mu \mathrm{m}$; that is, no refractive index modulation occurs in the fiber core.

2.2.2. Edge-Written LPFG with Periodic Grooves. Based on the method mentioned in Section 2.2.1, an edge-written LPFG with periodic grooves could be fabricated by increasing the laser energy [3]. The photograph of the grating structure is shown in Figure 4(a). The transmission spectrum evolution of the LPFG with a grating pitch of $400 \mu \mathrm{m}$ is shown in Figure 4(b).

By increasing the laser energy and enlarging the grating period of the E-LPFG, an ultra-long-period fiber grating with periodic grooves (G-ULPFG) distributed in outer cladding region of the fiber could be fabricated. The micrograph of a G-ULPFG with groove depth of $\sim 30 \mu \mathrm{m}$ and grating period of $2 \mathrm{~mm}$ is shown in Figure 5(a).
The transmission spectrum of the G-ULPFG is shown in Figure 5(b), indicating that the fundamental core mode couples with the cladding mode $\mathrm{LP}_{\mu k}$ of the $N$ th diffraction order [4]. That means every resonant peak of G-ULPFG has independent sensing sensitivity, which provides one way to realize multiparameters sensing by using one single sensor.

2.2.3. $L P F G$ with Rotary Refractive Index Modulation. To fabricate an LPFG with rotary refractive index modulation (R-LPFG), two ends of the fiber are fixed at two holders separated by a distance $L$, and the fiber is twisted by rotating a disc attached to one of the holders by $N$ circles, as shown in Figure 6. A normal twisted LPFG is fabricated in the fiber with a twist period $\Lambda_{T}=L / N$. Such an LPFG is referred to as T-LPFG [5]. The twist is removed by rotating the disc in opposite direction or releasing the fiber from the holders directly. Hence, there is a rotary refractive index modulation distribution along the fiber and it is referred to as R-LPFG. Unlike the LPFG with a screw-type index modulation, the rotary refractive index modulation of R-LPFG is discrete [52].

A comparison of the transmission spectra of several RLPFGs and the corresponding T-LPFGs is shown in Figure 7. The gratings have a period of $\Lambda_{G}=0.57 \mathrm{~mm}$ and a length of $L_{G}=28.5 \mathrm{~mm}$ (50 periods). When the twist period is larger than $\sim 60 \mathrm{~mm}, 2$ or 3 scanning cycles are needed to generate a strong T-LPFG. When the twist period is smaller than $\sim 60 \mathrm{~mm}$, however, only one scanning cycle is sufficient. As shown in Figure 7, the transmission spectrum of the T-LPFG consists of two rejection bands (at $\sim 1430$ and $\sim 1550 \mathrm{~nm}$ ) within the wavelength range of the broadband source, which correspond, respectively, to the couplings to two different orders of the cladding modes. The rejection bands of the T-LPFG are insensitive to the twist rate. On the other hand, the transmission spectrum of the R-LPFG is highly sensitive to the twist rate. At a low twist rate $\left(\Lambda_{T}=\right.$ $100 \mathrm{~mm}$ ), the spectrum of the R-LPFG is similar to that of the corresponding T-LPFG, which is expected. At a high twist 

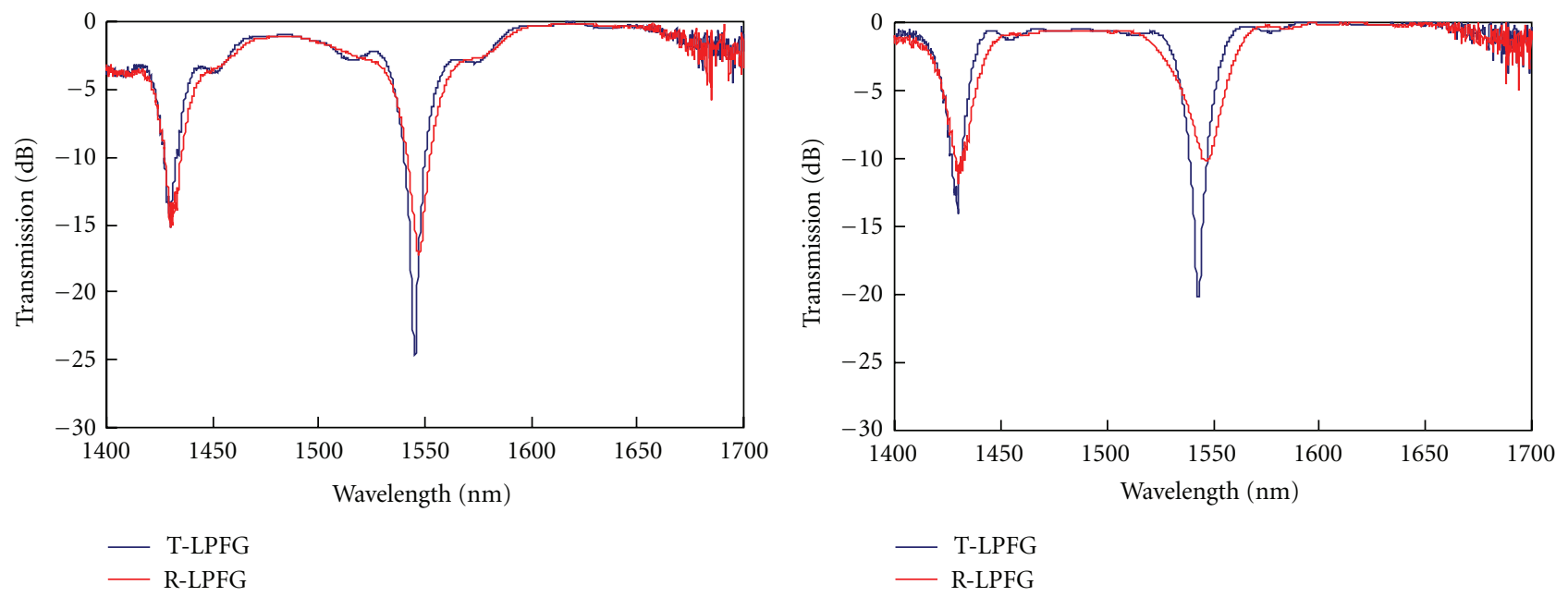

(a)
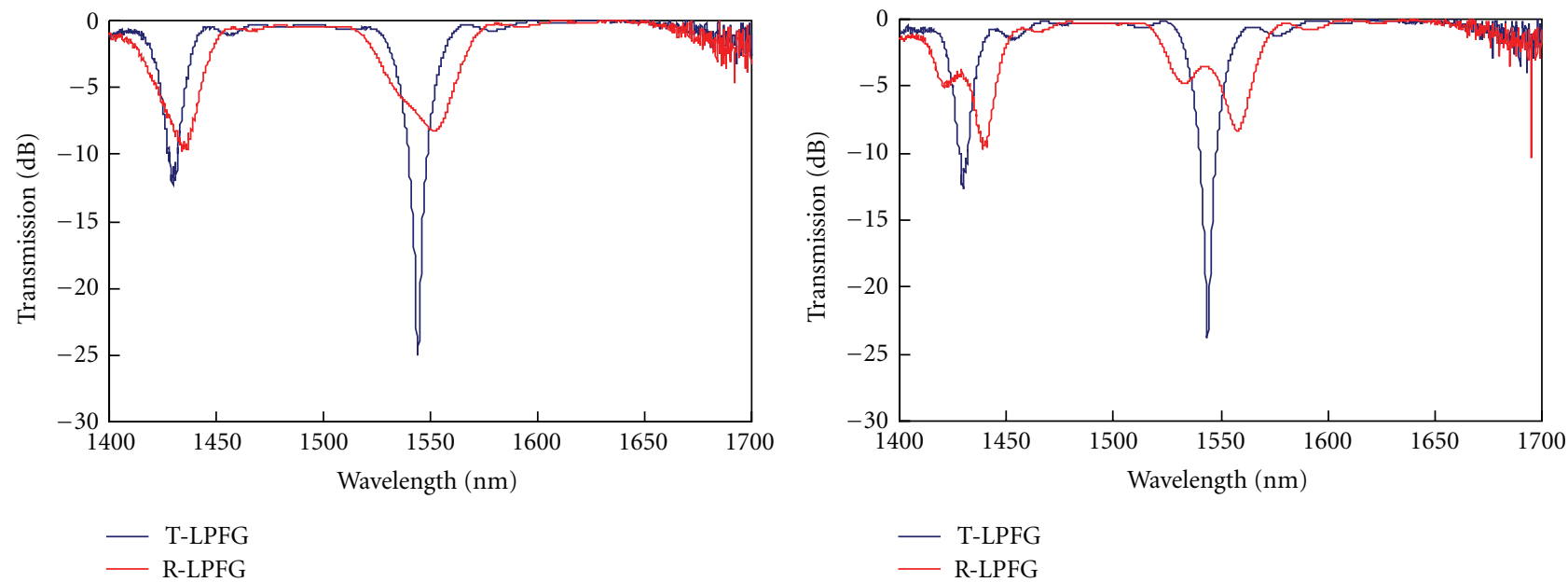

(c)

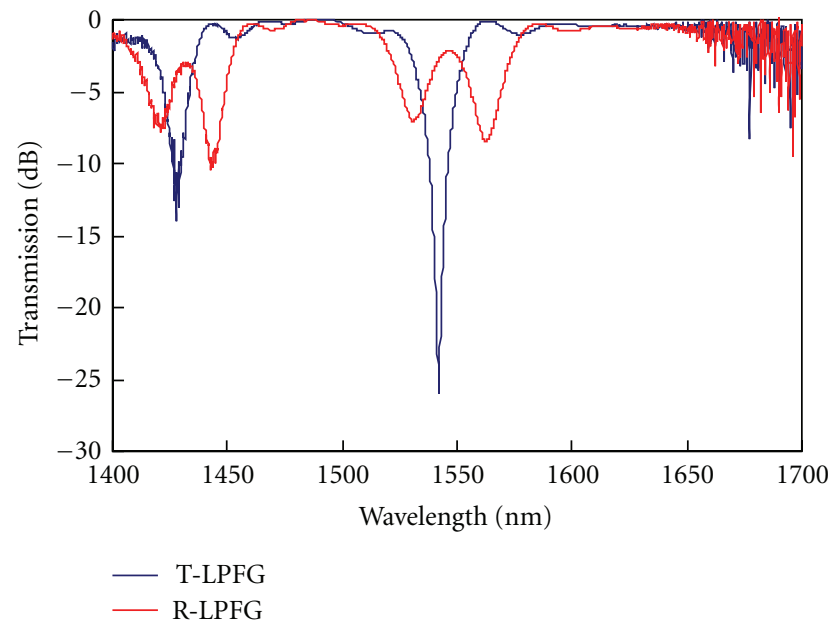

(e)

(d)

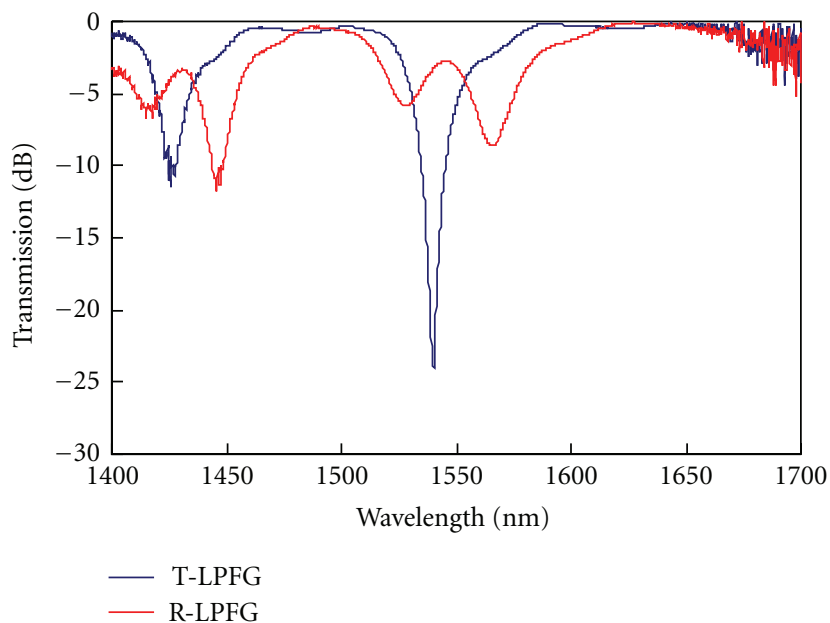

(f)

FigURE 7: Transmission spectra of a number of R-LPFGs and the corresponding T-LPFGs fabricated with different twist rates for a grating period of $\Lambda_{G}=0.57 \mathrm{~mm}$ and a grating length of $L_{G}=28.5 \mathrm{~mm}$ (50 periods): (a) $\Lambda_{T}=100 \mathrm{~mm}\left(L_{G} / \Lambda_{T}=0.285\right.$ ), (b) $\Lambda_{T}=75 \mathrm{~mm}$ $\left(L_{G} / \Lambda_{T}=0.38\right)$, (c) $\Lambda_{T}=60 \mathrm{~mm}\left(L_{G} / \Lambda_{T}=0.475\right)$, (d) $\Lambda_{T}=50 \mathrm{~mm}\left(L_{G} / \Lambda_{T}=0.57\right)$, (e) $\Lambda_{T}=37.5 \mathrm{~mm}\left(L_{G} / \Lambda_{T}=0.76\right)$, and (f) $\Lambda_{T}=30 \mathrm{~mm}\left(L_{G} / \Lambda_{T}=0.95\right)$ [5]. 


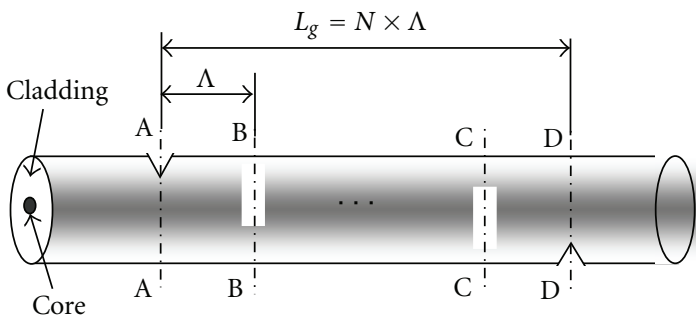

(a)

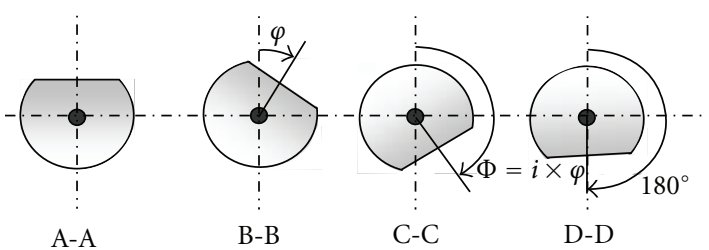

(b)

FIgURE 8: Structure of a grating with $N$ rotary grooves over a length of $L_{g}=N \Lambda$ [6]: (a) refractive modulation along the fiber axis, (b) refractive index distribution across the fiber cross section.

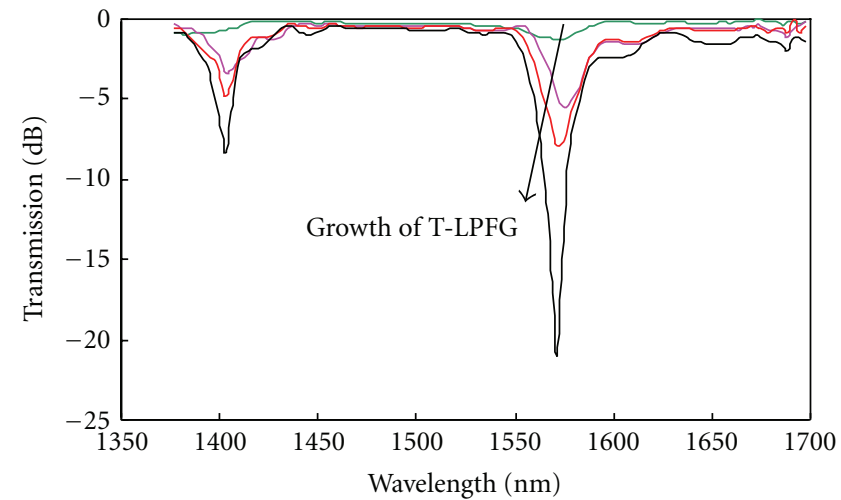

(a)

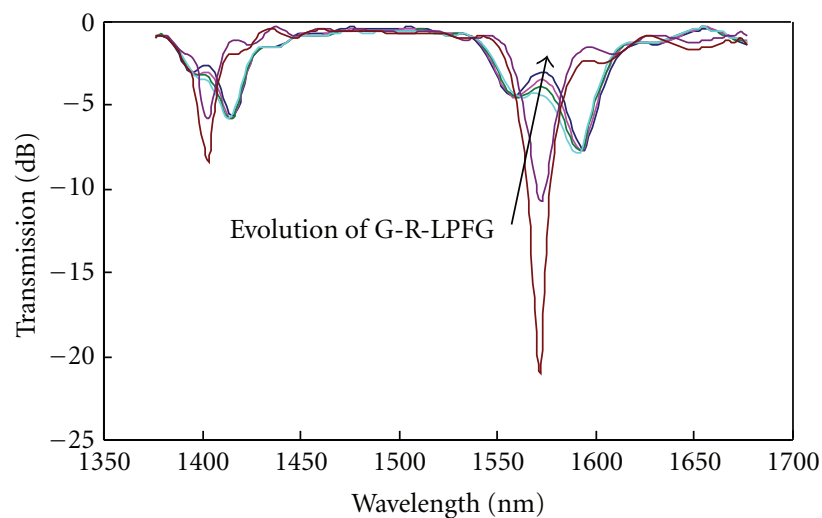

(b)

FIGURE 9: (a) Growth of the resonance peak of T-LPFG as the number of the scanning cycles increased. (b) Evolution of transmission of G-R-LPFG when the torsion was released [6].

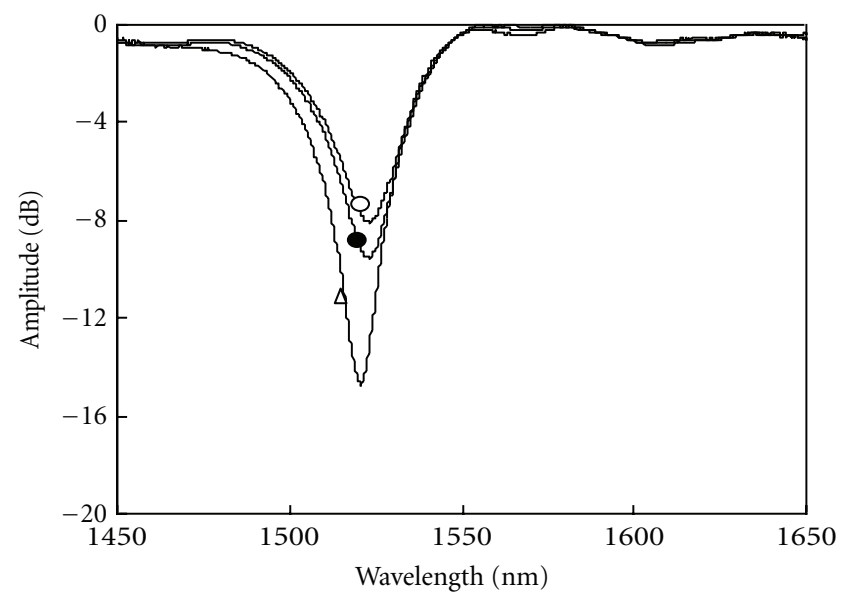

- 1st scanning cycle

- 2nd scanning cycle

$\Delta$ 3rd scanning cycle

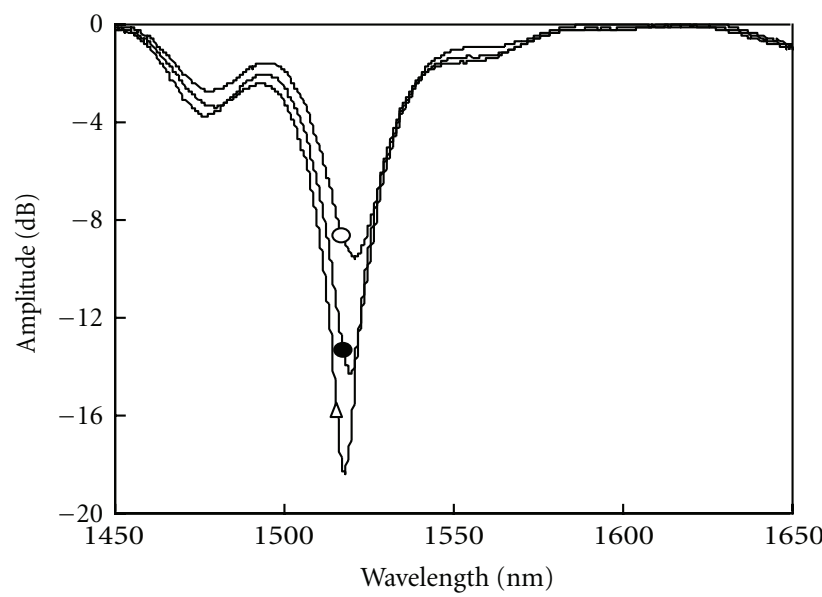

- 1st scanning cycle

- 2nd scanning cycle

$\Delta$ 3rd scanning cycle

(a)

(b)

FIGURE 10: Growth of the E-LPFGs with the same grating length of $2 \mathrm{~cm}$. (a) The writing depth is $\sim 15 \mu \mathrm{m}$. (b) The writing depth is $\sim 35 \mu \mathrm{m}$ [1]. 


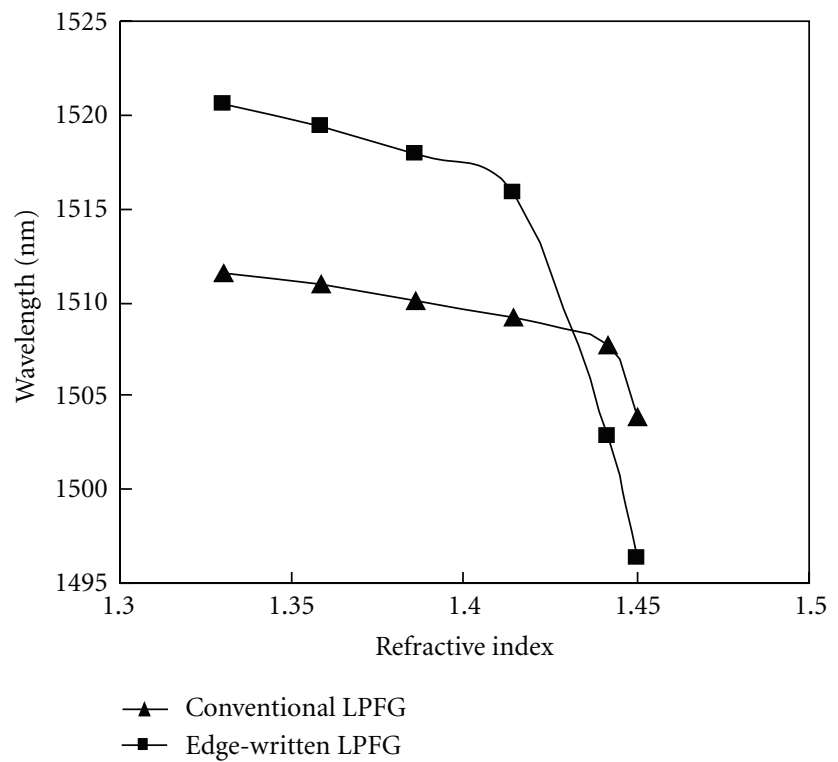

FIgURE 11: Refractive index responses of the E-LPFG and conventional LPFG [1].

rate $\left(\Lambda_{T}=37.5\right.$ and $\left.30 \mathrm{~mm}\right)$, each of the rejection bands is split into two completely. At a medium twist rate $\left(\Lambda_{T}=75\right.$, 60 , and $50 \mathrm{~mm}$ ), the split rejection bands overlap. It can be seen that the amount of wavelength splitting increases with the twist rate. The results show that untwisting a T-LPFG produces an R-LPFG whose characteristics depend strongly on the amount of applied twist in the writing of the T-LPFG.

2.2.4. LPFG with Rotary Grooves. According to the same procedure of R-LPFG fabrication, an LPFG with periodic grooves (G-R-LPFG) rotating along the fiber could be fabricated if the laser power is high enough to carve grooves on the cladding of the fiber [6]. The structure of a grating with $N$ rotary grooves over a length of $L_{g}=N \Lambda$ is shown in Figure 8. The fiber used is a conventional single-mode fiber (Corning, SMF-28). The grating period and the period number are $500 \mu \mathrm{m}$ and 60, respectively. Figure 9(a) shows the growth of the resonance peak of the T-LPFG during the writing of the grating, where the twist rate used is $\eta=6^{\circ} / \mathrm{mm}$. The resonance peak shifts towards shorter wavelength as the number of the scanning cycles increases, similar to the case of writing a normal LPFG with highfrequency $\mathrm{CO}_{2}$-laser pulses. Figure 9(b) shows the evolution of the G-R-LPFG. After the fiber is untwisted, two original resonance peaks of T-LPFG split into two smaller ones, respectively, and the coupling coefficients are different. For example, the peak at $1569.4 \mathrm{~nm}$ splits into two smaller ones at $1557.8 \mathrm{~nm}$ and $1593.7 \mathrm{~nm}$, respectively. The amplitudes of the two split peaks are $-4.92 \mathrm{~dB}$ and $-8.13 \mathrm{~dB}$. However, the peak at $1403.5 \mathrm{~nm}$ splits into two very weak ones. In the experiments, the peak splitting phenomena of the G-R-LPFG were not observed when twist rate $\eta$ is less than $3.6^{\circ} / \mathrm{mm}$ or so. It is a pity that the exact physical mechanism responsible for the observed phenomena is yet to be fully understood.

\section{Sensing Applications of Special LPFGs}

3.1. Refractometer. The transmission spectra of the E-LPFGs with different writing depths but same length are shown in Figure 10. It can be seen that the writing efficiency of the ELPFG with writing depth of $\sim 35 \mu \mathrm{m}$ is higher than that of $\sim 15 \mu \mathrm{m}$ since complete coupling between the core mode and higher order cladding modes needs a larger refractive index modulation.

To measure the ambient refractive index within the range of $1.33 \sim 1.45$ at room temperature, the E-LPFG with a writing depth of $\sim 15 \mu \mathrm{m}$ and grating period of $500 \mu \mathrm{m}$ is used. Compared with the conventional LPFG, the E-LPFG has much higher refractive index sensitivity, especially in higher refractive index range, as shown in Figure 11. The resonant wavelength shifts nonlinearly with respect to the refractive index and the wavelength of the E-LPFG shifts $\sim 24.2 \mathrm{~nm}$ for an index range from $1.33 \mu \mathrm{m}$ to $1.45 \mu \mathrm{m}$.

It should be noted that the temperature change will influence the refractive index measurement of E-LPFG. However, the cross effect could be decreased by employing G-ULPFG because there are several resonant peaks with different temperature and refractive index sensitivities due to the different coupling orders.

The refractive index responses of the resonant peaks ${ }^{N_{1}} \mathrm{LP}_{03}$ and ${ }^{N_{2}} \mathrm{LP}_{01}$ at room temperature are shown in Figures 12(a) and 12(b), respectively. As shown in Figure 12(c), the resonant peak ${ }^{N_{1}} \mathrm{LP}_{03}$ has little wavelength shift while the resonant peak ${ }^{N_{2}} \mathrm{LP}_{01}$ shifts nonlinearly toward shorter wavelength by $\sim 22 \mathrm{~nm}$ in the range of 1.33-1.45. But both of the resonant peaks shift toward the same direction with different temperature sensitivities. For the temperature range from $10^{\circ} \mathrm{C}$ to $100^{\circ} \mathrm{C}$, the temperature sensitivities of the resonant peaks ${ }^{N_{1}} \mathrm{LP}_{03}$ and ${ }^{{ }_{2}} \mathrm{LP}_{01}$ are $0.076 \mathrm{~nm} /{ }^{\circ} \mathrm{C}$ and $0.033 \mathrm{~nm} /{ }^{\circ} \mathrm{C}$, respectively, as shown in Figure 13. Therefore 


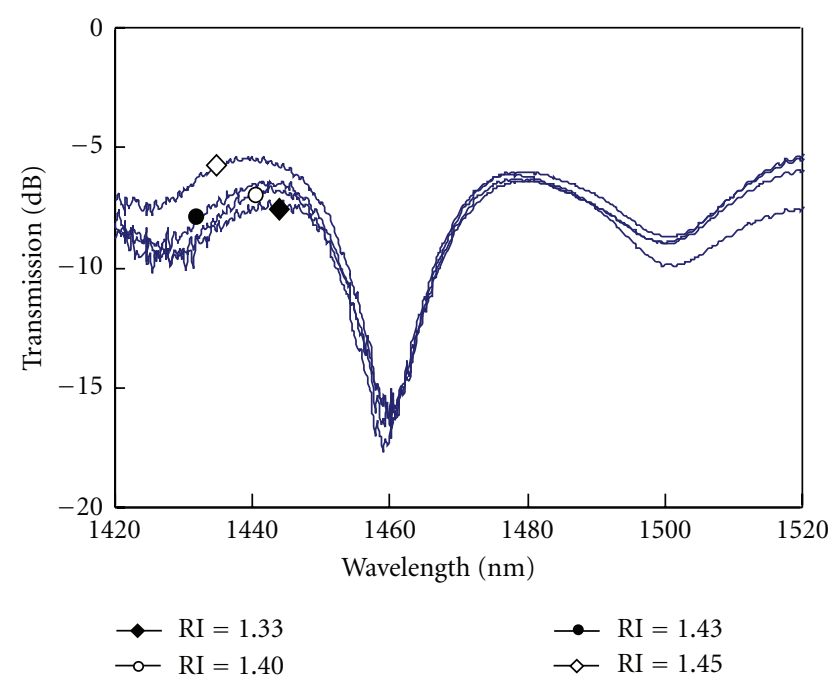

(a)

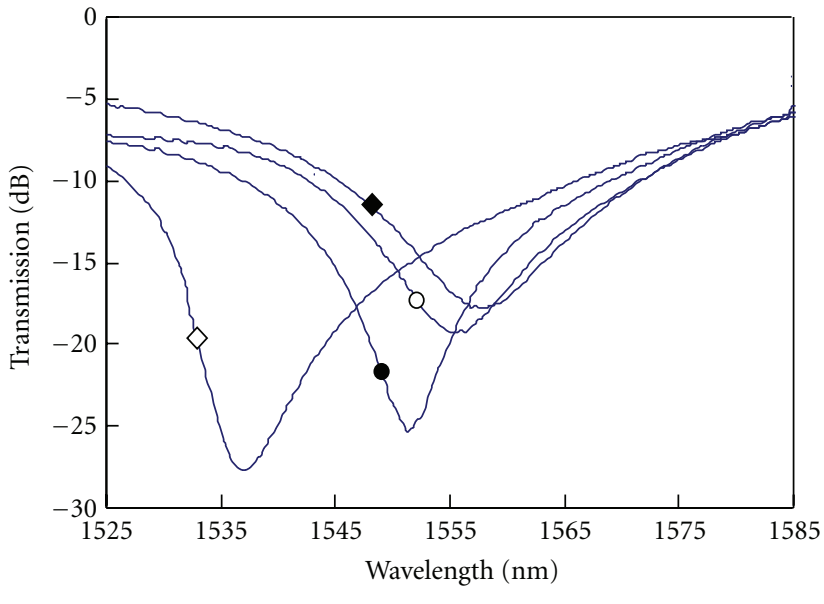

$\longrightarrow \mathrm{RI}=1.33$
$\multimap \mathrm{RI}=1.40$

$\rightarrow \mathrm{RI}=1.43$

$\leadsto \mathrm{RI}=1.45$

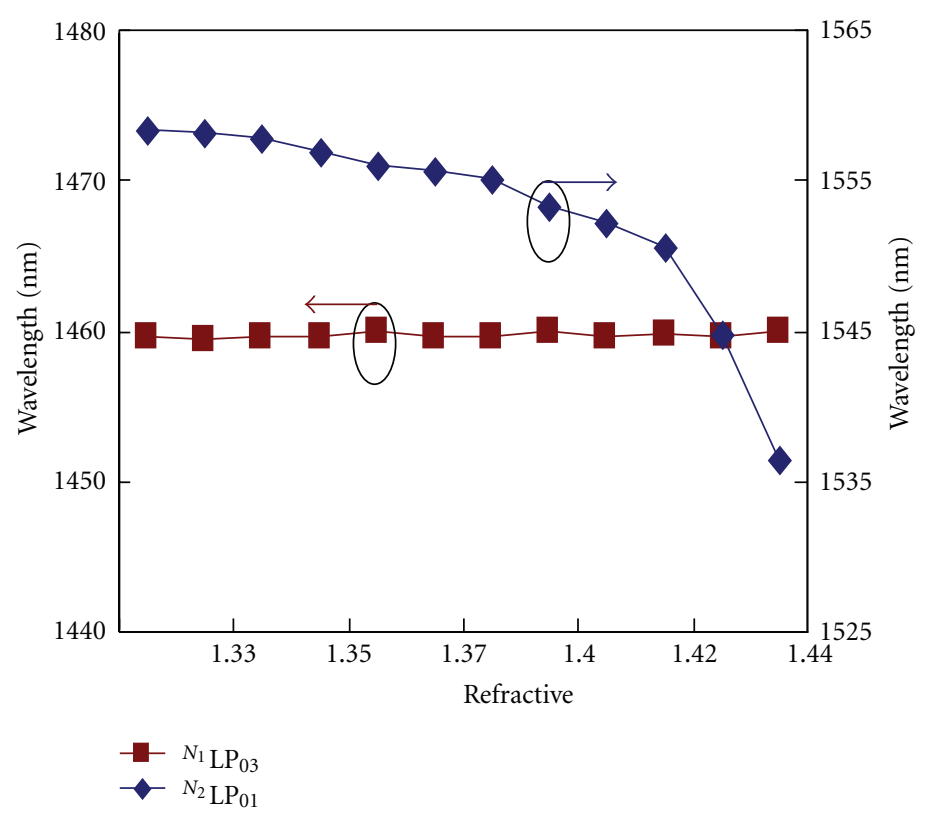

(c)

FIGURE 12: Refractive index response of the G-ULPFG [4]. (a) Spectra of resonant peak ${ }^{N_{1}} \mathrm{LP}_{03}$. (b) Spectra of resonant peak ${ }^{N_{2}} \mathrm{LP}_{01}$. (c) Wavelength shift of resonant peaks ${ }^{N_{1}} \mathrm{LP}_{03}$ and ${ }^{N_{2}} \mathrm{LP}_{01}$.

such a G-ULPFG could be used as a refractive index sensor with temperature self-compensation. The principle is that the resonant peak with higher differential order is used to measure refractive index while the resonant peak with a low differential order is used to measure temperature. Also the error of refractive index measurement based on its temperature characteristics should be compensated.

3.2. Torsion Sensor with Temperature Self-Compensation. It has been found that LPFGs fabricated by different methods demonstrate different torsion response. LPFGs induced by UV laser or mechanical pressure cannot be used to sense applied torsion while the LPFGs fabricated by electric-arc discharging, etching or $\mathrm{CO}_{2}$ laser irradiation can be used to measure the torsion rate and direction simultaneously $[36,52,58-61]$. However, the LPFGs induced by $\mathrm{CO}_{2}$ laser in SMF are also sensitive to temperature change, resulting in errors for torsion measurement [2]. To eliminate the cross effect of temperature change, an R-LPFG could be used as a torsion sensor. An LPFG with a period of $570 \mu \mathrm{m}$ and a length of $28.5 \mathrm{~mm}$ is fabricated in a twisted SMF with twist period of $30 \mathrm{~mm}$ and then released gradually. The transmission spectra of the T-LPFG and R-LPFG are shown in Figure 14, demonstrating the wavelength splitting phenomena. The wavelength separation between every two 


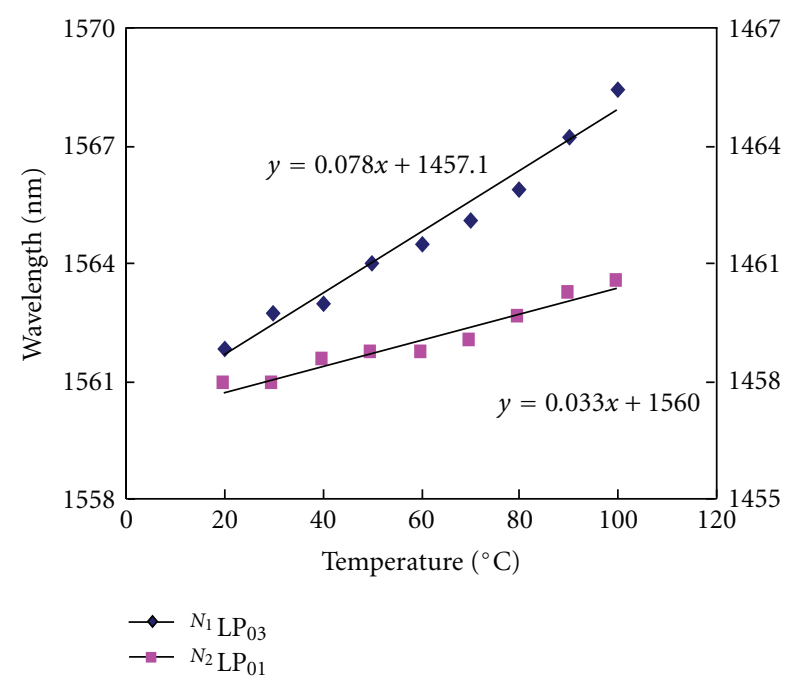

Figure 13: Wavelength shifts of the resonant peaks ${ }^{{ }_{1}} \mathrm{LP}_{03}$ and ${ }^{N_{2}} \mathrm{LP}_{01}$ with respect to temperature [4].

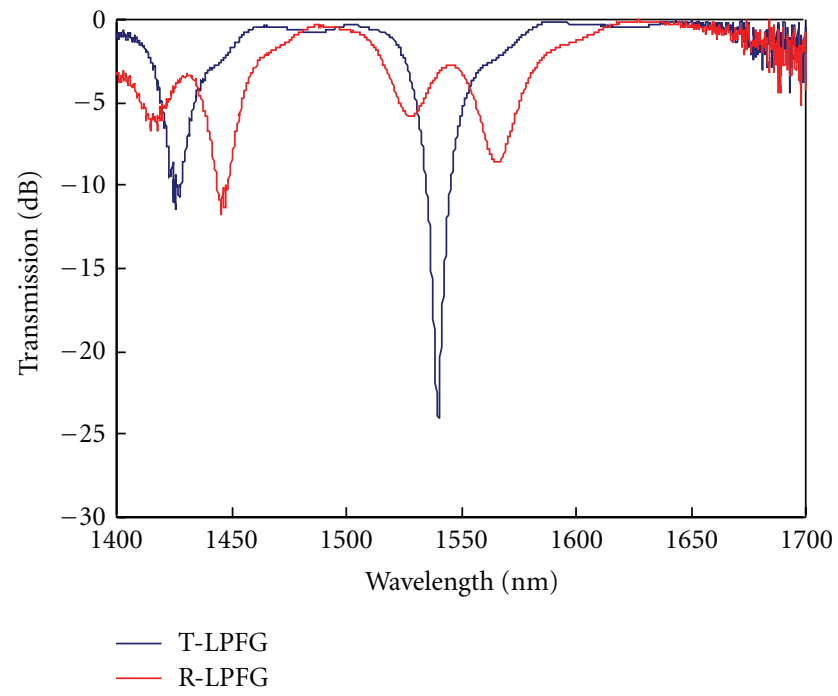

Figure 14: Transmission spectra of T-LPFG and R-LPFG [5].

regenerated resonant peaks changes with the applied torsion, as shown in Figures 15(a) and 15(b), enabling it to be useful for torsion measurement.

The temperature experiment of a 50-period R-LPFG with grating period of $570 \mu \mathrm{m}$ and twist period of $50 \mathrm{~mm}$ is shown in Figure 16. It can be seen that the temperature sensitivities of two split wavelengths are the same with a value of $\sim 0.07 \mathrm{~nm} /{ }^{\circ} \mathrm{C}$ and the changes in the amplitudes of two resonant peaks with temperature are small. Hence, the applied torsion could be measured without temperature cross effect by tracing the wavelength separation.

3.3. Strain Sensor. The LPFG formed by carving periodic grooves with $\mathrm{CO}_{2}$ laser has a strain sensitivity of $0.12 \mathrm{~nm} / \mu \varepsilon$ in the range from 0 to $100 \mu \varepsilon$ but suffers from temperature interference [3]. Although R-LPFGs could be used as strain sensors with temperature self compensation [62], the strain sensitivity of the R-LPFG is only $\sim 0.0053 \mathrm{~nm} / \mu \varepsilon$. Like RLPFGs, wavelength splitting also occurs in G-R-LPFGs when the applied torsion is released, as shown in Figure 17. Moreover the experimental results show that the temperature sensitivities of $\lambda_{1}$ and $\lambda_{2}$ separated by $33.6 \mathrm{~nm}$ are $0.072 \mathrm{~nm} /{ }^{\circ} \mathrm{C}$ and $0.0726 \mathrm{~nm} /{ }^{\circ} \mathrm{C}$, respectively, indicating that it is insensitive to temperature vibration.

The strain responses of $\lambda_{1}$ and $\lambda_{2}$ are shown in Figures 18 (a) and $18(\mathrm{~b})$, respectively. Within $700 \mu \varepsilon$ the strain sensitivities of $\lambda_{1}$ and $\lambda_{2}$ are $-0.05237 \mathrm{~nm} / \mu \varepsilon$ and $+0.053 \mathrm{~nm} / \mu \varepsilon$, respectively. The separation between the two wavelengths as a function of strain is shown in Figure 18(c), demonstrating that the strain sensitivity of the G-R-LPFG is $0.1067 \mathrm{~nm} / \mu \varepsilon$ when the strain is less than $700 \mu \varepsilon$. The sensitivity of the GR-LPFG is much higher than that of R-LPFG ( 20 times).

\section{Demodulation of LPFGs}

4.1. Wavelength Shift. Most of the LPFG-based sensors are demodulated by wavelength shift since it is easy to trace the shift with the help of optical spectrum analyzer (OSA). However the OSA is generally very expensive and bulky, increasing the cost and decreasing the flexibility of the measurement system. Moreover, the bandwidth of the LPFG is much broader than that of the FBG, implying that it requires higher resolution OSA to minimize the measurement error. Another inconvenience for demodulating the LPFGs is that the light source and demodulation terminals are separated since LPFGs work in the transmission mode. To overcome the difficulties, the transmission spectrum of the LPFG is inverted by putting a mirror in the cladding region of a fiber end-face to reflect only the cladding modes [63]. The end face mirror can be realized through four steps: (a) to fabricate an LPFG, (b) to make a polymetric microtip using photopolymer, (c) to coat the fiber end face with sputtering deposition, (d) to break the microtip under CCD camera. The typical grating structure is shown in Figure 19. However, the inherent broad bandwidth of the LPFG limits the precision of measurements when the measurement is realized by means of wavelength shift.

4.2. Intensity Demodulation. For some LPFGs, the amplitudes of resonant peaks change with the strain, ambient refractive index or other perturbations, leading to that the LPFGs can be demodulated by monitoring the intensity vibrations of resonant peaks. One solution to intensity demodulation proposed by Wang et al. is shown in Figure 19 [7]. The light from the broadband light source LED with symmetric spectrum near the resonant wavelength $\lambda_{0}$ of the LPFG is equally divided into two parts by a $3 \mathrm{~dB}$ coupler $\left(C_{0}\right)$ and then illuminates $\mathrm{FBG}_{1}$ and $\mathrm{FBG}_{2}$ with Bragg wavelengths of $\lambda_{1}$ and $\lambda_{2}$, respectively. $\lambda_{1}$ and $\lambda_{2}$ should be specially selected to satisfy the relation $\lambda_{1}+\lambda_{2} \approx 2 \lambda_{0}$. The light reflected by $\mathrm{FBG}_{1}$ and $\mathrm{FBG}_{2}$ is directed to an LPFG and received by $\mathrm{PD}_{1}$ and $\mathrm{PD}_{2}$, respectively. By subtracting the intensities $I_{1}$ and $I_{2}$ detected by $\mathrm{PD}_{1}$ and $\mathrm{PD}_{2}$, the intensity fluctuations at $\lambda_{1}$ and $\lambda_{2}$ could be eliminated and 


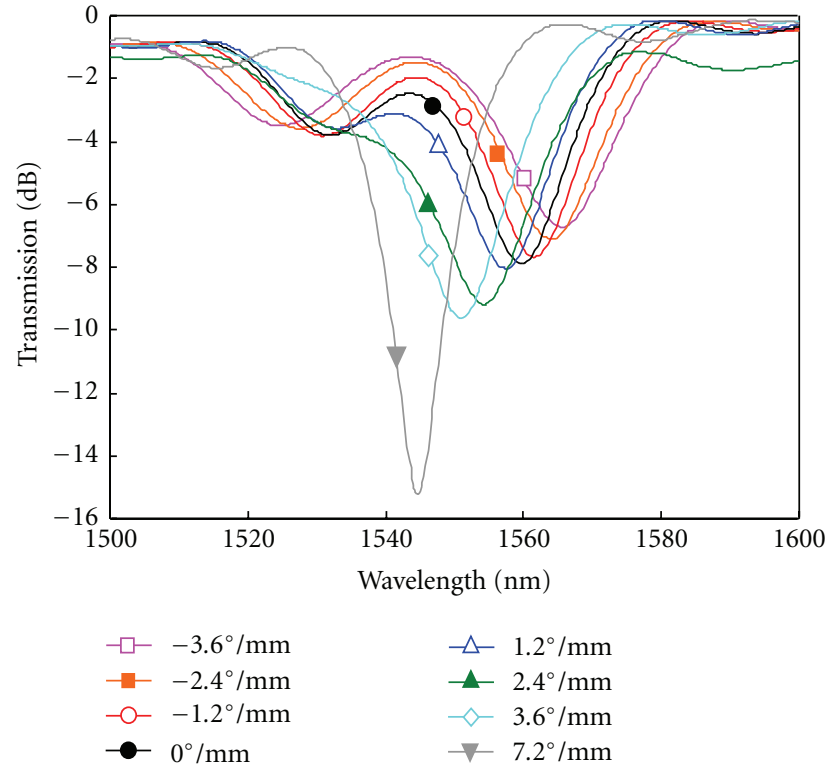

(a)

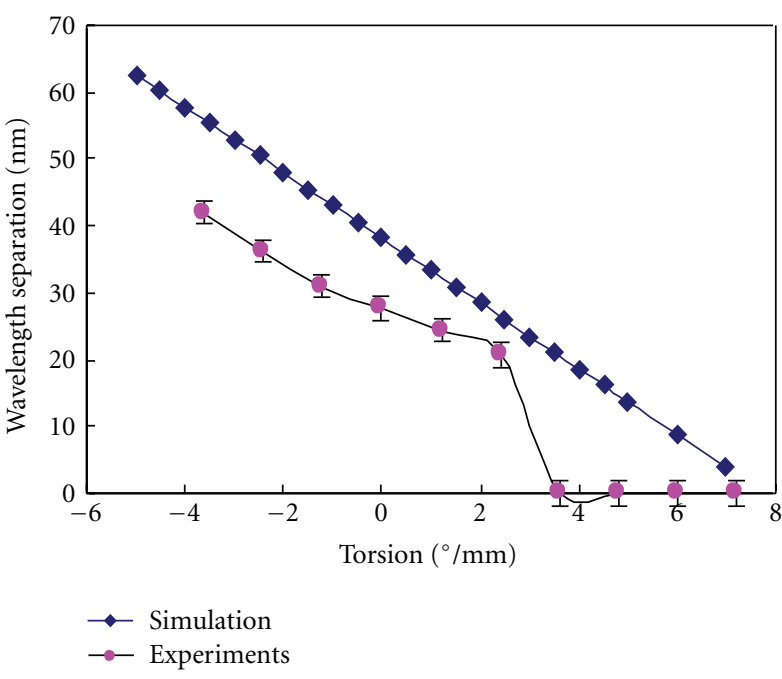

(b)

FIGURE 15: (a) Transmission spectra of R-LPFG with grating period of $570 \mu \mathrm{m}$ and twist period of $46 \mathrm{~mm}$ under different torsion, where "+" and "-" mean that the direction of the applied torsion is the same or opposite to that of the original twist applied to the fiber, respectively. (b) Wavelength separation of resonant peaks with respect to applied torsion [5].

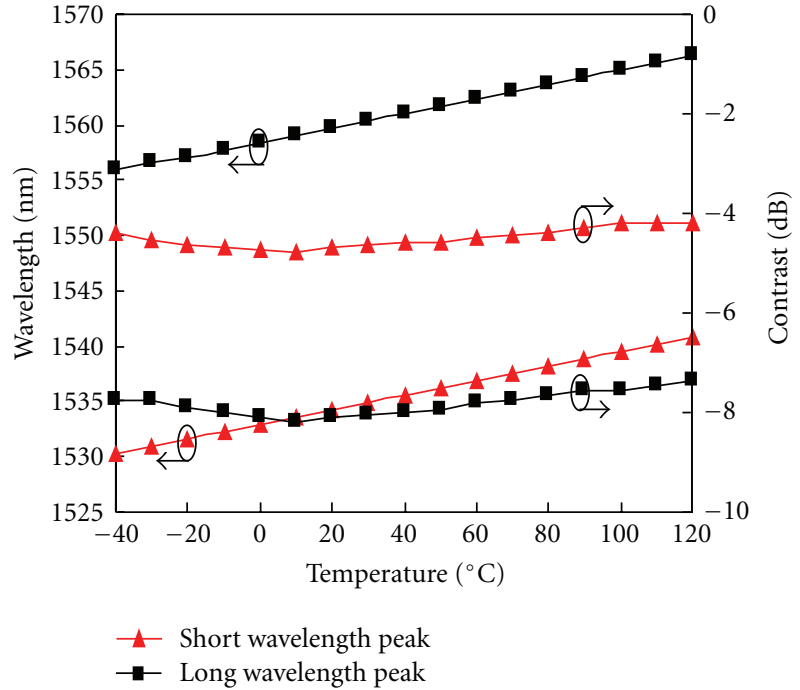

Figure 16: Temperature characteristics of the R-LPFG [5].

the temperature sensitivity could also be doubled by this method.

Another solution to intensity demodulation is to detect the intensity at a certain wavelength that is slightly larger than the resonant wavelength [64]. Therefore only a monochromatic source is needed to illuminate the LPFG and the variation in core power could be measured by a power meter, reducing the cost but increasing the robustness of the system. It is also convenient to realize real-time measurement with this method. However, it has the problem of limiting the measurement range of the LPFG since the transmission spectrum of LPFG is symmetric with respect to the resonant wavelength.

4.3. Fiber Ring Laser Investigation. The interferometric sensor based on Mach-Zehnder interferometers (MZIs) with two cascaded R-LPFGs could also be used as a multichannel bandpass filter, as shown in Figure 20(a). When the MZI is incorporated into a standard fiber ring cavity, the wavelength with the highest intensity in the transmission spectrum of the MZI will be chosen as the lasing wavelength of the fiber ring laser [8]. And the lasing wavelength shifts with the torsions applied to the MZI. For example, the emitting wavelength of the fiber ring laser shifts $\sim 16 \mathrm{~nm}$ in the torsion range of $\pm 100 \mathrm{rad} / \mathrm{m}$, as shown in Figure 20(b) [8]. Also, the method could be used to measure refractive index, temperature, and strain.

Compared with the passive LPFG-based sensors, the sensors demodulated by using fiber ring laser can realize more precise measurement since the fiber laser has narrower linewidth and higher side-mode suppression ratio $(\sim 40 \mathrm{~dB})$. It can be found from Figure 20(b) that the laser spectra are similar to that of the FBGs, which means that all the demodulation methods applicable to FBGs can be used to demodulate the LPFG-based interferometric sensors.

4.4. Remote Sensing Based on LPFGs and Fiber Ring Laser. Most of the LPFG-based sensors are demodulated by the wavelength shift, where an expensive optical spectrum analyzer (OSA) is indispensable. Moreover it is inconvenient for remote measurement where the light source and OSA are 


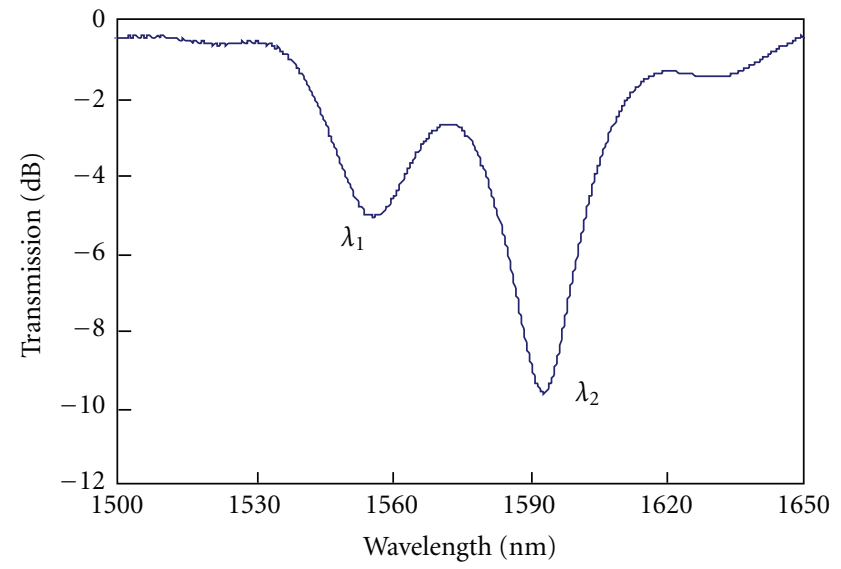

FIGURE 17: Splitting of the resonance peak after the fiber is untwisted [6].

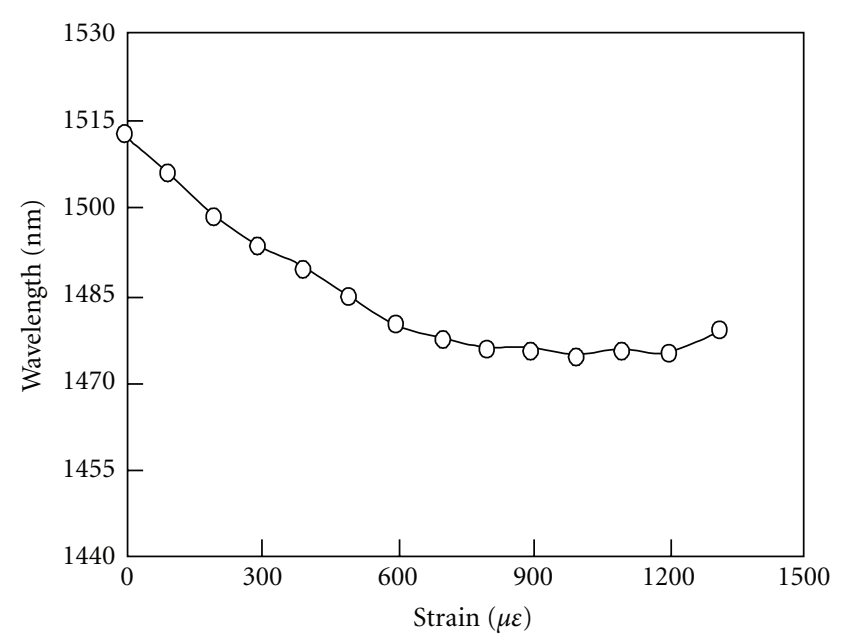

(a)

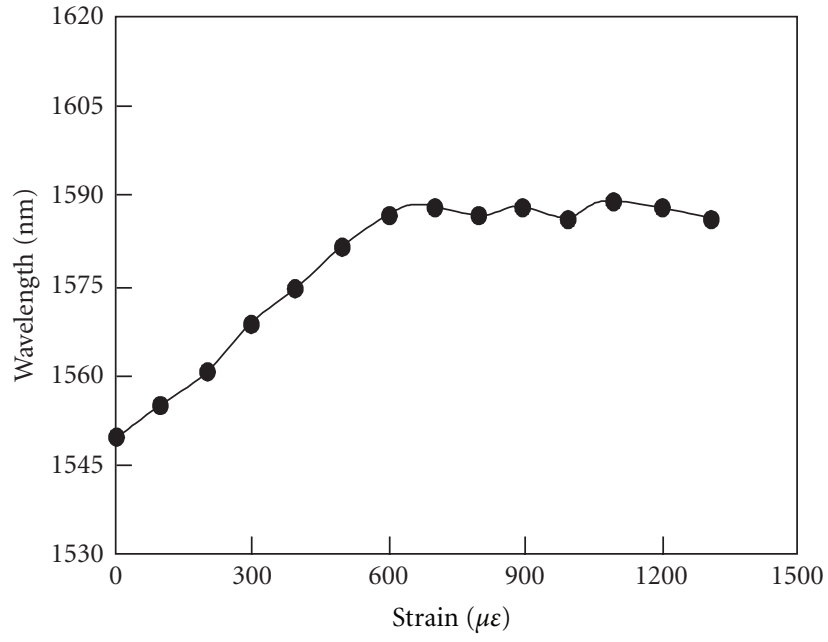

(b)

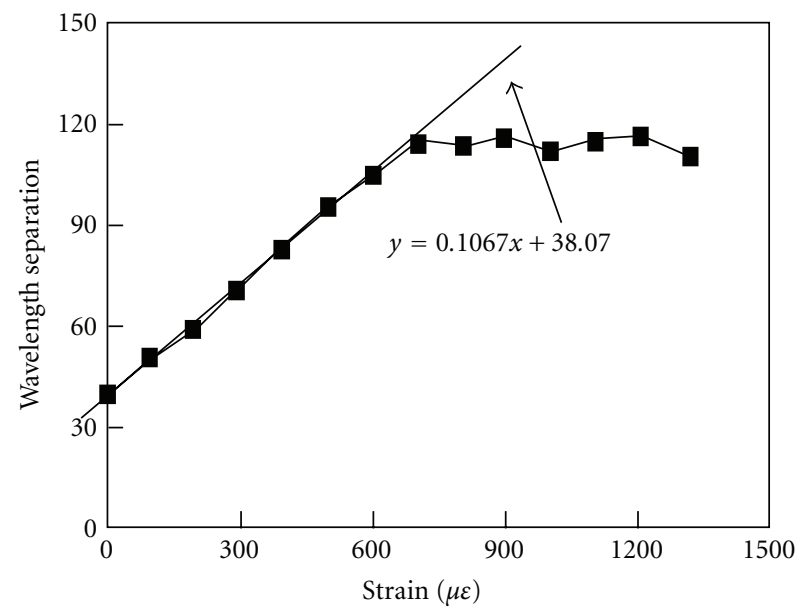

(c)

FIGURE 18: (a) Strain characteristics of $\lambda_{1}$. (b) Strain characteristics of $\lambda_{2}$. (c) Wavelength separation between $\lambda_{1}$ and $\lambda_{2}$ with respect to strain [6]. 


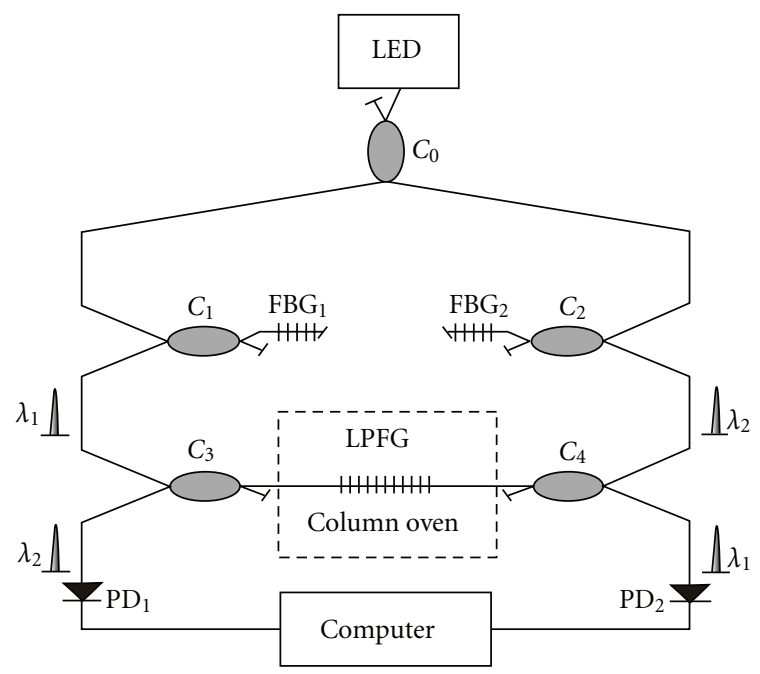

FIGURE 19: Schematic diagram of the $\mathrm{CO}_{2}$ laser-grooved LPFG temperature sensor system based on the intensity modulation. $C_{1}, C_{2}, C_{3}$, and $C_{4}$ are $3 \mathrm{~dB}$ couplers [7].

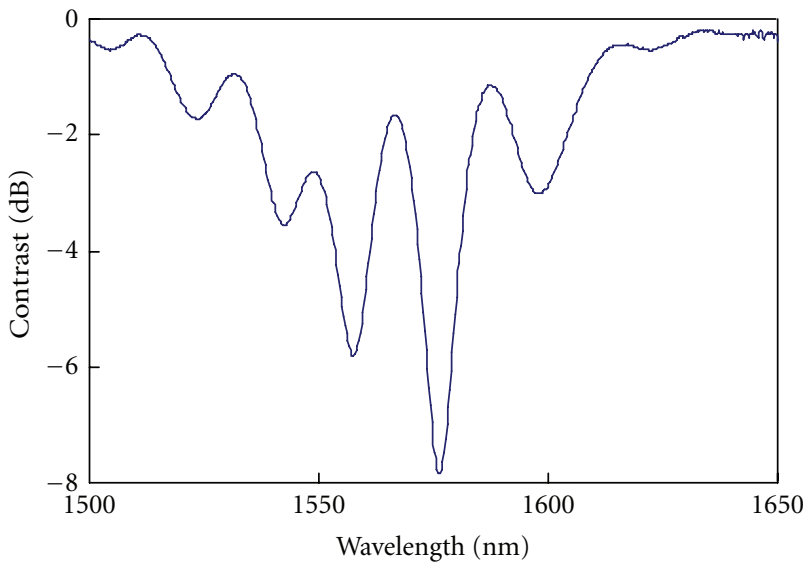

(a)

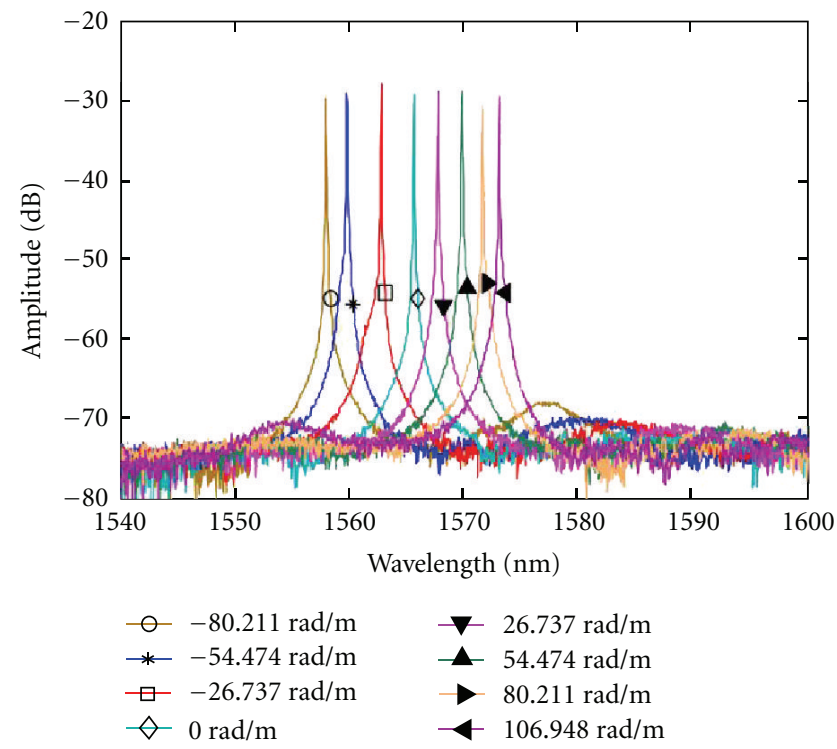

(b)

Figure 20: (a) Transmission spectrum of the MZI. The separation of the two gratings was $33.0 \mathrm{~mm}$ and each grating consisted of 30 periods with a pitch of $435 \mu \mathrm{m}$. The gratings are fabricated in a twisted fiber with a twist period of $3.92 \mathrm{~cm}$. (b) Lasing wavelength shift with torsion applied to the MZI. "-" means that the direction of the applied torsion is the same as that of the original torsion applied to the fiber [8].

separated by long distance since LPFG works in the transmission mode. To overcome this difficulty, the transmission spectrum of the LPFG is inverted by making a mirror on the cladding region of a fiber end face to reflect the cladding modes. The reflected cladding modes are coupled back to the core by the same LPFG, resulting in pass bands centered at the resonant wavelengths of the LPFG. However, the inherent broad bandwidth of the LPFG limits the precision of measurements when the measurement is realized by means of wavelength shift. Recently, a remote sensing system based on LPFG and fiber ring laser is presented [65]. The stopband in the transmission spectrum of the LPFG is inverted into a pass-band by fusion splicing a piece of HCF to the grating. Then such an inverted LPFG is employed in the master and slave ring laser, in which the grating is used as the wavelength selector and sensor head simultaneously. The temperature experiment shows that such a system can measure the temperature more than $1 \mathrm{~km}$ away and the sensitivity is $\sim 0.02 \mathrm{~nm} /{ }^{\circ} \mathrm{C}$ within the range of $20-150^{\circ} \mathrm{C}$.

The remote sensing schematic diagram is shown in Figure 21 [65]. The LPFG with band pass characteristics working in the reflective mode is used as sensor and band pass filter simultaneously, which is shown schematically in Figure 22(a). The input light is coupled to the cladding by the 


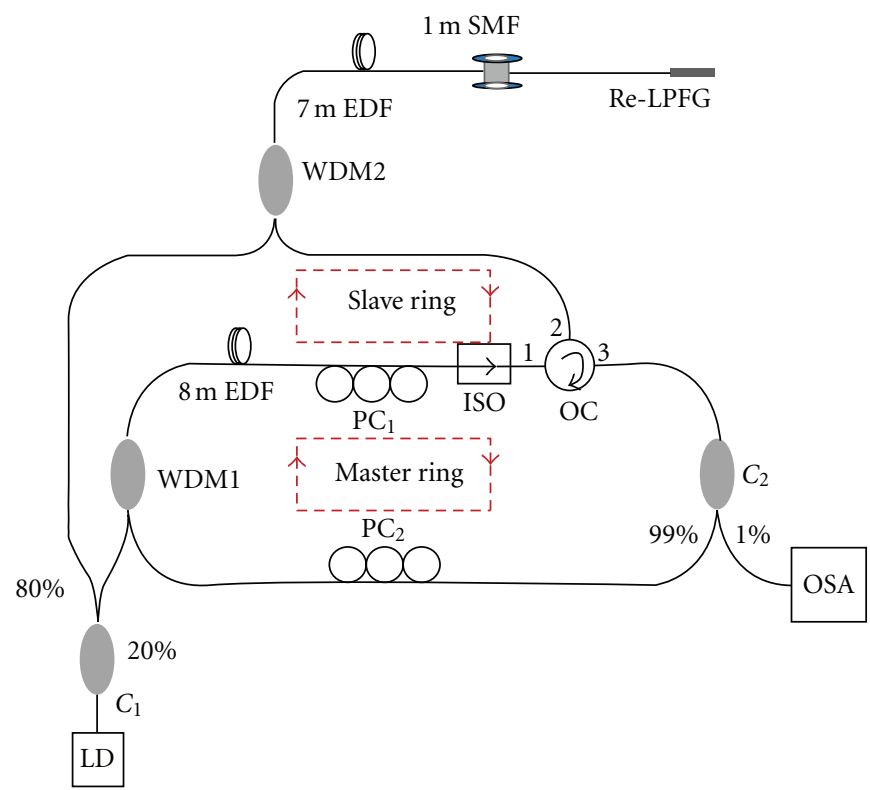

FIGURE 21: Schematic diagram of the system for the reflective band pass LPFG demodulated by fiber ring laser. $C_{1}: 20: 80$ coupler, LD: laser diode, WDM1 and WDM2: 980/1550 nm wavelength division multiplexer, EDF: erbium-doped fiber, Re-LPFG: reflective band pass filter, $\mathrm{PC}_{1}$ and $\mathrm{PC}_{2}$ : polarization controller, ISO: isolator, $\mathrm{OC}$ : optical circulator, and $C_{2}: 1: 99$ coupler.

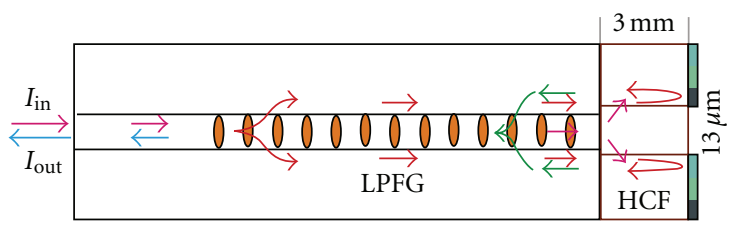

(a)

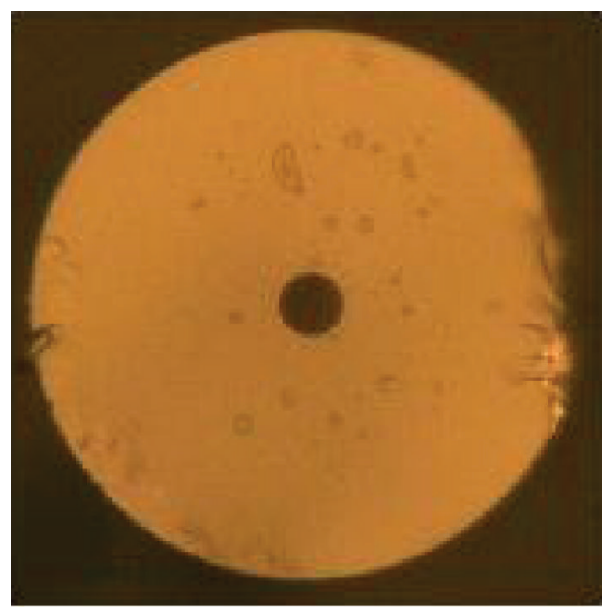

(b)

Figure 22: (a) The schematic diagram of the LPFG-based sensor. (b) Micrograph of the HCF cross section.

LPFG and propagates along the fiber as cladding mode and reflected by the cladding-air interface of the hollow core fiber (HOF). The microscope of the cross section of the HOF is shown in Figure 22(b), showing that the diameter of the core is $\sim 13 \mu \mathrm{m}$. The input light that propagates in the SMF core leaks into the HOF cladding since the refractive index of the core in HOF is less than that of the cladding. And the Fresnel reflection occurs in the core-air interface when the SMF and $\mathrm{HCF}$ are reduced by increasing the arc discharge of the splicer and push distance of the SMF when the SMF and HOF are fusion-spliced. Therefore a pass band instead of interference formed at the output when the cladding mode is coupled to the core. The spectra of the LPFG and the reflective bandpass LPFG are shown in Figure 23.

When the temperature around the LPFG is gradually increased from $20^{\circ} \mathrm{C}$ to $150^{\circ} \mathrm{C}$ with a step of $10^{\circ} \mathrm{C}$ and stayed for $10 \mathrm{~min}$ at each step. The laser output and wavelength shift are shown in Figure 24(a) and Figure 24(b), respectively. It can be found from Figure 24(a) that the laser output is very similar to the reflect spectrum of an FBG. The demodulation method of the Re-LPFG could be changed from the original wavelength shift completed by the OSA to those that have been used widely by the FBG, such as tunable F-P filter, linear edge filter, and interferometer. Figure 24(b) shows 


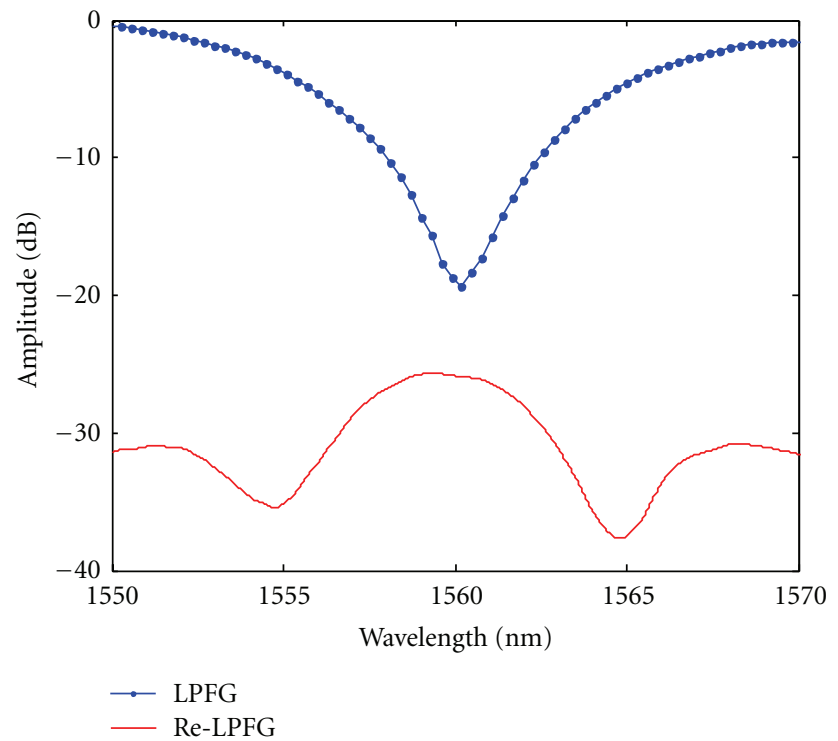

FIGURE 23: Spectra of LPFG and reflective LPFG.

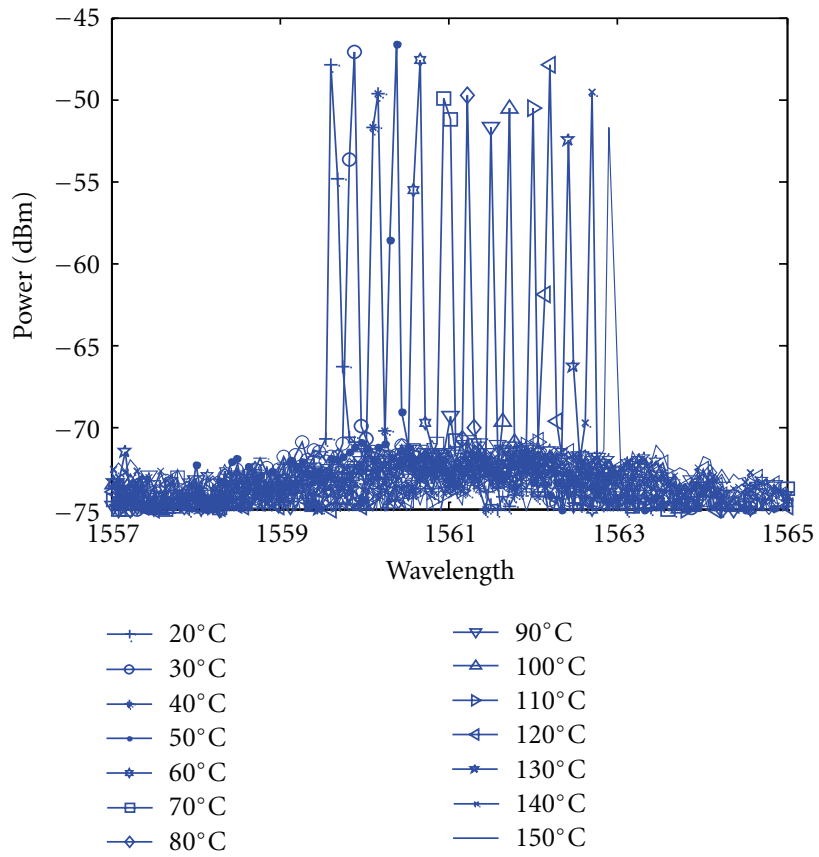

(a)

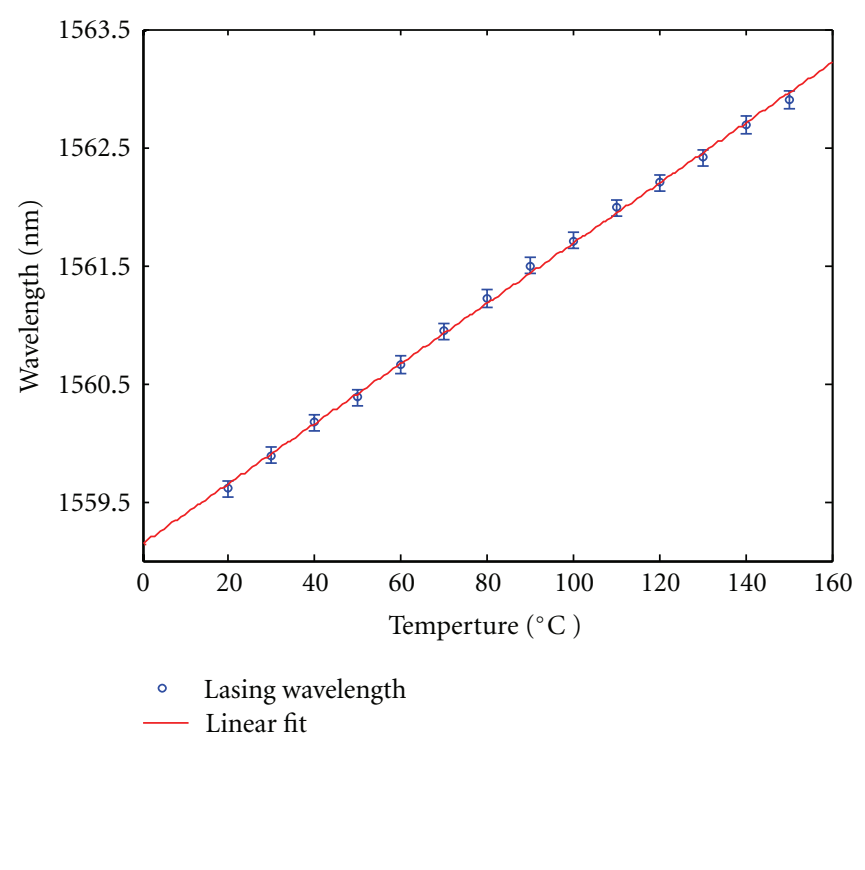

(b)

FIgURE 24: (a) The laser output under different temperatures and (b) laser wavelength shift with the temperature.

such a sensor has a temperature sensitivity of $\sim 0.02 \mathrm{~nm} /{ }^{\circ} \mathrm{C}$ within the range of $20-150^{\circ} \mathrm{C}$. The main reason for the measurement error shown in Figure 24(b) is the instability of the laser, which is caused by the inherent asymmetric grating structure of single-side irradiation-induced LPFG. It has been shown that the resonant wavelength of the LPFG written by single side $\mathrm{CO}_{2}$ laser irradiation method shifts to $\sim 0.2 \mathrm{~nm}$ when two orthogonally polarized lights are coupled into the LPFG, respectively. The central wavelength of the bandpass signal that determines the lasing wavelength of the fiber ring laser is also sensitive to the change in the state of polarization (SOP). The measurement error could be improved if the good symmetric LPFGs were fabricated by multiedge exposure of $\mathrm{CO}_{2}$ laser, or by rotating the fiber during the exposure process. Besides, the resolution limit of the OSA also contributes to the error. 


\section{Conclusion}

The paper presents a review of special LPFGs fabricated by scanning $\mathrm{CO}_{2}$ laser, including edge-written LPFGs, LPFGs/ULPFGs with periodic grooves, LPFGs fabricated in twisted fibers, and LPFG with rotary grooves. As for the refractive index sensor, torsion sensor, or strain sensor, the sensitivities of the special LPFGs are higher than that of the normal LPFGs induced by $\mathrm{CO}_{2}$ laser. More importantly, some of the special LPFGs could realize temperature selfcompensation, avoiding the cross effect between temperature and other measurands. Compared with the wavelength shift and intensity demodulation methods, fiber ring laser investigation method is more competitive since broadband source and OSA are not required and the methods for FBG demodulation can also be used. The special LPFGs could be widely used in optical sensing fields due to its high sensitivity, temperature self-compensation, and easy demodulation.

\section{Acknowledgments}

This work is supported by the Project of Nature Science Foundation of China under Grants no. 61007049 and 60807019 and the Program for NCET (Grant no. NCET-080602).

\section{References}

[1] T. Zhu, Y. J. Rao, J. L. Wang, and Y. Song, "A highly sensitive fiber-optic refractive index sensor based on an edge-written long-period fiber grating," IEEE Photonics Technology Letters, vol. 19, no. 24, pp. 1946-1948, 2007.

[2] Y. J. Rao, Y. P. Wang, Z. L. Ran, and T. Zhu, "Novel fiber-optic sensors based on long-period fiber gratings written by highfrequency $\mathrm{CO}_{2}$ laser pulses," Journal of Lightwave Technology, vol. 21, no. 5, pp. 1320-1327, 2003.

[3] Y. P. Wang, D. N. Wang, W. Jin, Y. J. Rao, and G. D. Peng, "Asymmetric long period fiber gratings fabricated by use of $\mathrm{CO}_{2}$ laser to carve periodic grooves on the optical fiber," Applied Physics Letters, vol. 89, no. 15, Article ID 151105, 2006.

[4] T. Zhu, Y. Song, Y. J. Rao, and Y. Zhu, "Highly sensitive optical refractometer based on edge-written ultra-long-period fiber grating formed by periodic grooves," IEEE Sensors Journal, vol. 9, no. 6, pp. 678-681, 2009.

[5] T. Zhu, K. S. Chiang, Y. J. Rao, C. H. Shi, Y. Song, and M. Liu, "Characterization of long-period fiber gratings written by $\mathrm{CO}_{2}$ laser in twisted single-mode fibers," Journal of Lightwave Technology, vol. 27, no. 21, pp. 4863-4869, 2009.

[6] T. Zhu, Y. J. Rao, Y. Song, K. S. Chiang, and M. Liu, "Highly sensitive temperature-independent strain sensor based on a long-period fiber grating with a $\mathrm{CO}_{2}$-laser engraved rotary structure," IEEE Photonics Technology Letters, vol. 21, no. 8, pp. 543-545, 2009.

[7] Y. P. Wang, D. N. Wang, and W. Jin, " $\mathrm{CO}_{2}$ laser-grooved long period fiber grating temperature sensor system based on intensity modulation," Applied Optics, vol. 45, no. 31, pp. 7966-7970, 2006.

[8] L. L. Shi, T. Zhu, Y. E. Fan, K. S. Chiang, and Y. J. Rao, “Torsion sensing with a fiber ring laser incorporating a pair of rotary long-period fiber gratings," Optics Communications, vol. 284, no. 22, pp. 5299-5302, 2011.
[9] A. M. Vengsarkar, P. J. Lemaire, J. B. Judkins, V. Bhatia, T. Erdogan, and J. E. Sipe, "Long-period fiber gratings as bandrejection filters," Journal of Lightwave Technology, vol. 14, no. 1, pp. 58-64, 1996.

[10] V. Bhatia and A. M. Vengsarkar, "Optical fiber long-period grating sensors," Optics Letters, vol. 21, no. 9, pp. 692-694, 1996.

[11] H. Kawano, H. Muentz, Y. Sato, J. Nishimae, and A. Sugitatsu, "Reduction of transmission spectrum shift of long-period fiber gratings by a UV-preexposure method," Journal of Lightwave Technology, vol. 19, no. 8, pp. 1221-1227, 2001.

[12] B. O. Guan, H. Y. Tam, S. L. Ho, S. Y. Liu, and X. Y. Dong, "Growth of long-period gratings in $\mathrm{H}_{2}$-loaded fiber after 193nm UV inscription," IEEE Photonics Technology Letters, vol. 12, no. 6, pp. 642-644, 2000.

[13] X. Chen, K. Zhou, L. Zhang, and I. Bennion, "Optical biochemical sensors based on long-period fibre gratings UVinscribed in D-fibre with enhanced sensitivity by HF etching process," in Proceedings of the SPIE International Conference on Advanced Laser Technologies: Biomedical Optics (ALT '03), vol. 5486, pp. 187-191, September 2003.

[14] I. K. Hwang, S. H. Yun, and B. Y. Kim, "Long-period fiber gratings based on periodic microbends," Optics Letters, vol. 24, no. 18, pp. 1263-1265, 1999.

[15] G. Humbert and A. Malki, "Characterizations at very high temperature of electric arc-induced long-period fiber gratings," Optics Communications, vol. 208, no. 4-6, pp. 329-335, 2002.

[16] G. Rego and O. Ivanov, "Investigation of the mechanisms of formation of long-period gratings arc-induced in pure-silicacore fibres," Optics Communications, vol. 284, no. 8, pp. 21372140, 2011.

[17] W. J. Bock, J. Chen, P. Mikulic, T. Eftimov, and M. KorwinPawlowski, "Pressure sensing using periodically tapered longperiod gratings written in photonic crystal fibres," Measurement Science and Technology, vol. 18, no. 10, pp. 3098-3102, 2007.

[18] G. Humbert, A. Malki, and M. Ketata, "Long-period fiber gratings filters fabrications and characterizations using electric arc in non-hydrogenated fibers," in Proceedings of the SPIE Active and Passive Optical Components for WDM Communication, vol. 4532, pp. 510-516, August 2001.

[19] G. Rego and O. V. Ivanov, "Two types of resonances in long-period gratings induced by arc discharges in boron/germanium co-doped fibers," Optics Letters, vol. 32, no. 20, pp. 2984-2986, 2007.

[20] D. D. Davis, T. K. Gaylord, E. N. Glytsis, S. G. Kosinski, S. C. Mettler, and A. M. Vengsarkar, "Long-period fibre grating fabrication with focused $\mathrm{CO}_{2}$ laser pulses," Electronics Letters, vol. 34, no. 3, pp. 302-303, 1998.

[21] D. D. Davis, T. K. Gaylord, E. N. Glytsis, and S. C. Mettler, " $\mathrm{CO}_{2}$ laser-induced long-period fibre gratings: spectral characteristics, cladding modes and polarisation independence," Electronics Letters, vol. 34, no. 14, pp. 1416-1417, 1998.

[22] D. D. Davis, T. K. Gaylord, E. N. Glytsis, and S. C. Mettler, "Very-high-temperature stable $\mathrm{CO}_{2}$-laser-induced longperiod fibre gratings," Electronics Letters, vol. 35, no. 9, pp. 740-742, 1999.

[23] G. Kakarantzas, T. E. Dimmick, T. A. Birks, R. Le Roux, and P. S. J. Russell, "Miniature all-fiber devices based on $\mathrm{CO}_{2}$ laser microstructuring of tapered fibers," Optics Letters, vol. 26, no. 15, pp. 1137-1139, 2001.

[24] G. Kakarantzas, T. A. Birks, and P. S. J. Russell, "Structural long-period gratings in photonic crystal fibers," Optics Letters, vol. 27, no. 12, pp. 1013-1015, 2002. 
[25] Y. Zhu, P. Shum, J. H. Chong, M. K. Rao, and C. Lu, "Deepnotch, ultracompact long-period grating in a large-mode-area photonic crystal fiber," Optics Letters, vol. 28, no. 24, pp. 24672469, 2003.

[26] Y. Wang, L. Xiao, D. N. Wang, and W. Jin, "In-fiber polarizer based on a long-period fiber grating written on photonic crystal fiber," Optics Letters, vol. 32, no. 9, pp. 1035-1037, 2007.

[27] H. W. Lee, Y. Liu, and K. S. Chiang, "Writing of long-period fiber gratings in conventional and photonic-crystal polarization-maintaining fibers by $\mathrm{CO}_{2}$ laser pulses," IEEE Photonics Technology Letters, vol. 20, no. 2, pp. 132-134, 2008.

[28] Y. Wang, W. Jin, J. Ju et al., "Long period gratings in air-core photonic bandgap fibers," Optics Express, vol. 16, no. 4, pp. 2784-2790, 2008.

[29] H. Xuan, W. Jin, and M. Zhang, " $\mathrm{CO}_{2}$ laser induced long period gratings in optical microfibers," Optics Express, vol. 17, no. 24, pp. 21882-21890, 2009.

[30] S. Savin, M. J. F. Digonnet, G. S. Kino, and H. J. Shaw, "Tunable mechanically induced long-period fiber gratings," Optics Letters, vol. 25, no. 10, pp. 710-712, 2000.

[31] T. S. Lee, N. A. George, P. Sureshkumar, P. Radhakrishnan, C. P. G. Vallabhan, and V. P. N. Nampoori, "Chemical sensing with microbent optical fiber," Optics Letters, vol. 26, no. 20, pp. 1541-1543, 2001.

[32] J. Y. Cho and K. S. Lee, "A birefringence compensation method for mechanically induced long-period fiber gratings," Optics Communications, vol. 213, no. 4-6, pp. 281-284, 2002.

[33] L. Su, K. S. Chiang, and C. Lu, "Microbend-induced mode coupling in a graded-index multimode fiber," Applied Optics, vol. 44, no. 34, pp. 7394-7402, 2005.

[34] P. Steinvurzel, E. D. Moore, E. C. Mägi, B. T. Kuhlmey, and B. J. Eggleton, "Long period grating resonances in photonic bandgap fiber," Optics Express, vol. 14, no. 7, pp. 3007-3014, 2006.

[35] D. Lee, Y. Jung, Y. S. Jeong et al., "Highly polarizationdependent periodic coupling in mechanically induced long period grating over air-silica fibers," Optics Letters, vol. 31, no. 3, pp. 296-298, 2006.

[36] C. Y. Lin, L. A. Wang, and G. W. Chern, "Corrugated longperiod fiber gratings as strain, torsion, and bending sensors," Journal of Lightwave Technology, vol. 19, no. 8, pp. 1159-1168, 2001.

[37] L. A. Wang, C. Y. Lin, and G. W. Chern, "A torsion sensor made of a corrugated long period fibre grating," Measurement Science and Technology, vol. 12, no. 7, pp. 793-799, 2001.

[38] O. V. Ivanov and L. A. Wang, "Wavelength shifts of claddingmode resonance in corrugated long-period fiber gratings under torsion," Applied Optics, vol. 42, no. 13, pp. 2264-2272, 2003.

[39] W. Ding and S. R. Andrews, "Modal coupling in surfacecorrugated long-period-grating fiber tapers," Optics Letters, vol. 33, no. 7, pp. 717-719, 2008.

[40] M. Fujimaki, Y. Ohki, J. L. Brebner, and S. Roorda, "Fabrication of long-period optical fiber gratings by use of ion implantation," Optics Letters, vol. 25, no. 2, pp. 88-89, 2000.

[41] M. L. von Bibra, A. Roberts, and J. Canning, "Fabrication of long-period fiber gratings by use of focused ion-beam irradiation," Optics Letters, vol. 26, no. 11, pp. 765-767, 2001.

[42] Y. Kondo, K. Nouchi, T. Mitsuyu, M. Watanabe, P. G. Kazansky, and K. Hirao, "Fabrication of long-period fiber gratings by focused irradiation of infrared femtosecond laser pulses," Optics Letters, vol. 24, no. 10, pp. 646-648, 1999.

[43] E. Fertein, C. Przygodzki, H. Delbarre, A. Hidayat, M. Douay, and P. Niay, "Refractive-index changes of standard telecommunication fiber through exposure to femtosecond laser pulses at $810 \mathrm{~cm}$," Applied Optics, vol. 40, no. 21, pp. 3506-3508, 2001.

[44] F. Hindle, E. Fertein, C. Przygodzki et al., "Inscription of longperiod gratings in pure silica and germano-silicate fiber cores by femtosecond laser irradiation," IEEE Photonics Technology Letters, vol. 16, no. 8, pp. 1861-1863, 2004.

[45] A. I. Kalachev, V. Pureur, and D. N. Nikogosyan, "Investigation of long-period fiber gratings induced by high-intensity femtosecond UV laser pulses," Optics Communications, vol. 246, no. 1-3, pp. 107-115, 2005.

[46] A. I. Kalachev, D. N. Nikogosyan, and G. Brambilla, "Longperiod fiber grating fabrication by high-intensity femtosecond pulses at $211 \mathrm{~nm}$," Journal of Lightwave Technology, vol. 23, no. 8, pp. 2568-2578, 2005.

[47] T. Allsop, M. Dubov, A. Martinez et al., "Bending characteristics of fiber long-period gratings with cladding index modified by femtosecond laser," Journal of Lightwave Technology, vol. 24, no. 8, pp. 3147-3154, 2006.

[48] S. Liu, L. Jin, W. Jin, Y. Wang, and D. N. Wang, "Fabrication of long-period gratings by femtosecond laser-induced filling of air-holes in photonic crystal fibers," IEEE Photonics Technology Letters, vol. 22, no. 22, pp. 1635-1637, 2010

[49] C. Lião, Y. Wang, D. N. Wang, and L. Jin, "Femtosecond laser inscribed long-period gratings in all-solid photonic bandgap fibers," IEEE Photonics Technology Letters, vol. 22, no. 6, pp. 425-427, 2010.

[50] B. J. O'Regan and D. N. Nikogosyan, "Femtosecond UV long-period fiber grating fabrication with amplitude mask technique," Optics Communications, vol. 284, no. 24, pp. 56505654, 2011.

[51] Y. Zhu, P. Shum, H. W. Bay, X. Chen, C. H. Tan, and C. $\mathrm{Lu}$, "Wide-passband, temperature-insensitive, and compact $\pi$ phase-shifted long-period gratings in endlessly single-mode photonic crystal fiber," Optics Letters, vol. 29, no. 22, pp. 26082610, 2004.

[52] S. Oh, K. R. Lee, U. C. Paek, and Y. Chung, "Fabrication of helical long-period fiber gratings by use of a Co 2 laser," Optics Letters, vol. 29, no. 13, pp. 1464-1466, 2004.

[53] Y. P. Wang, L. Xiao, D. N. Wang, and W. Jin, "Highly sensitive long-period fiber-grating strain sensor with low temperature sensitivity," Optics Letters, vol. 31, no. 23, pp. 3414-3416, 2006.

[54] Y. J. Rao, T. Zhu, and Q. J. Mo, "Highly sensitive fiber-optic torsion sensor based on an ultra-long-period fiber grating," Optics Communications, vol. 266, no. 1, pp. 187-190, 2006.

[55] T. Zhu, Y. J. Rao, and J. L. Wang, "Characteristics of novel ultra-long-period fiber gratings fabricated by high-frequency $\mathrm{CO}_{2}$ laser pulses," Optics Communications, vol. 277, no. 1, pp. 84-88, 2007.

[56] T. Zhu, Y. J. Rao, and J. L. Wang, "Multi-edge-written longperiod fibre gratings with low PDL by using high-frequency $\mathrm{CO}_{2}$ Laser Pulses," Chinese Physics Letters, vol. 24, no. 7, pp. 1971-1972, 2007.

[57] Y. E. Fan, T. Zhu, L. L. Shi, and Y. J. Rao, "Fabrication and characteristics of phase-shifted beat gratings induced by $\mathrm{CO}_{2}$ laser," Microwave and Optical Technology Letters, vol. 53, no. 11, pp. 2526-2530, 2011.

[58] Z. Zhang, W. Shi, K. Gao, and Z. Fang, "Twist characteristics of the ultraviolet-written long-period fiber gratings," Chinese Optics Letters, vol. 2, no. 10, pp. 565-567, 2004.

[59] D. E. Ceballos-Herrera, I. Torres-Gomez, A. Martinez-Rios, L. Garcia, and J. J. Sanchez-Mondragon, "Torsion sensing characteristics of mechanically induced long-period holey 
fiber gratings," IEEE Sensors Journal, vol. 10, no. 7, pp. 12001205, 2010.

[60] Y. P. Wang and Y. J. Rao, "Long period fibre grating torsion sensor measuring twist rate and determining twist direction simultaneously," Electronics Letters, vol. 40, no. 3, pp. 164-166, 2004.

[61] P. Caldas, G. Rego, O. V. Ivanov, and J. L. Santos, "Characterization of the response of a dual resonance of an arc-induced long-period grating to various physical parameters," Applied Optics, vol. 49, no. 16, pp. 2994-2999, 2010.

[62] T. Zhu, Y. J. Rao, J. L. Wang, and Y. Song, "Strain sensor without temperature compensation based on LPFG with strongly rotary refractive index modulation," Electronics Letters, vol. 43, no. 21, pp. 1132-1134, 2007.

[63] M. Jiang, A. P. Zhang, Y. C. Wang, H. Y. Tam, and S. He, "Fabrication of a compact reflective long-period grating sensor with a cladding-mode-selective fiber end-face mirror," Optics Express, vol. 17, no. 20, pp. 17976-17982, 2009.

[64] A. Kapoor and E. K. Sharma, "Long period grating refractiveindex sensor: optimal design for single wavelength interrogation," Applied Optics, vol. 48, no. 31, pp. G88-G94, 2009.

[65] L. L. Shi, T. Zhu, Q. Zhang, and Y. J. Rao, "Remote sensing based on reflective bandpass long period fiber grating and fiber ring laser," in Proceedings of the 22nd International Conference on Optical Fiber Sensors, Beijing, China, October 2012, No. 20128421-211. 

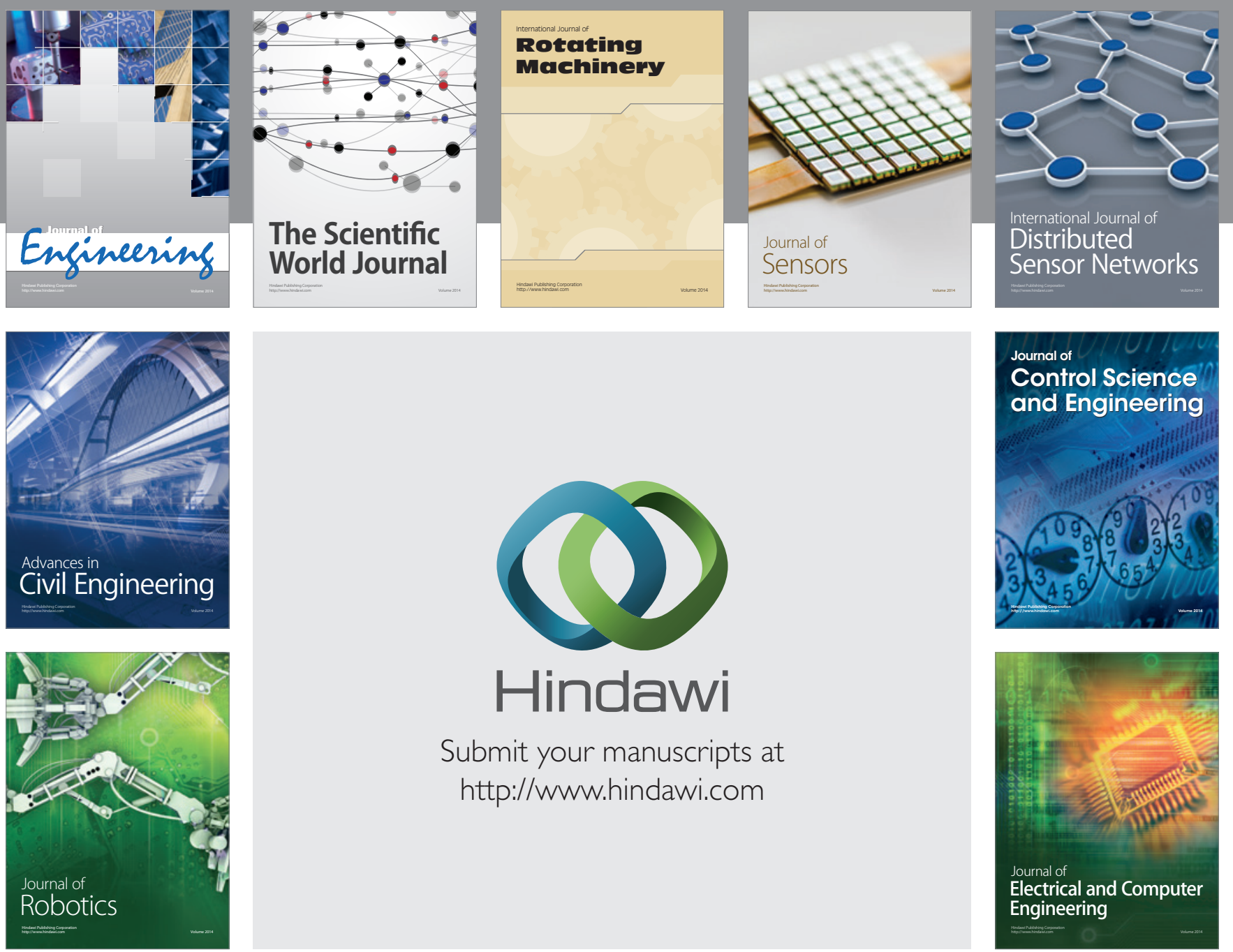

Submit your manuscripts at

http://www.hindawi.com
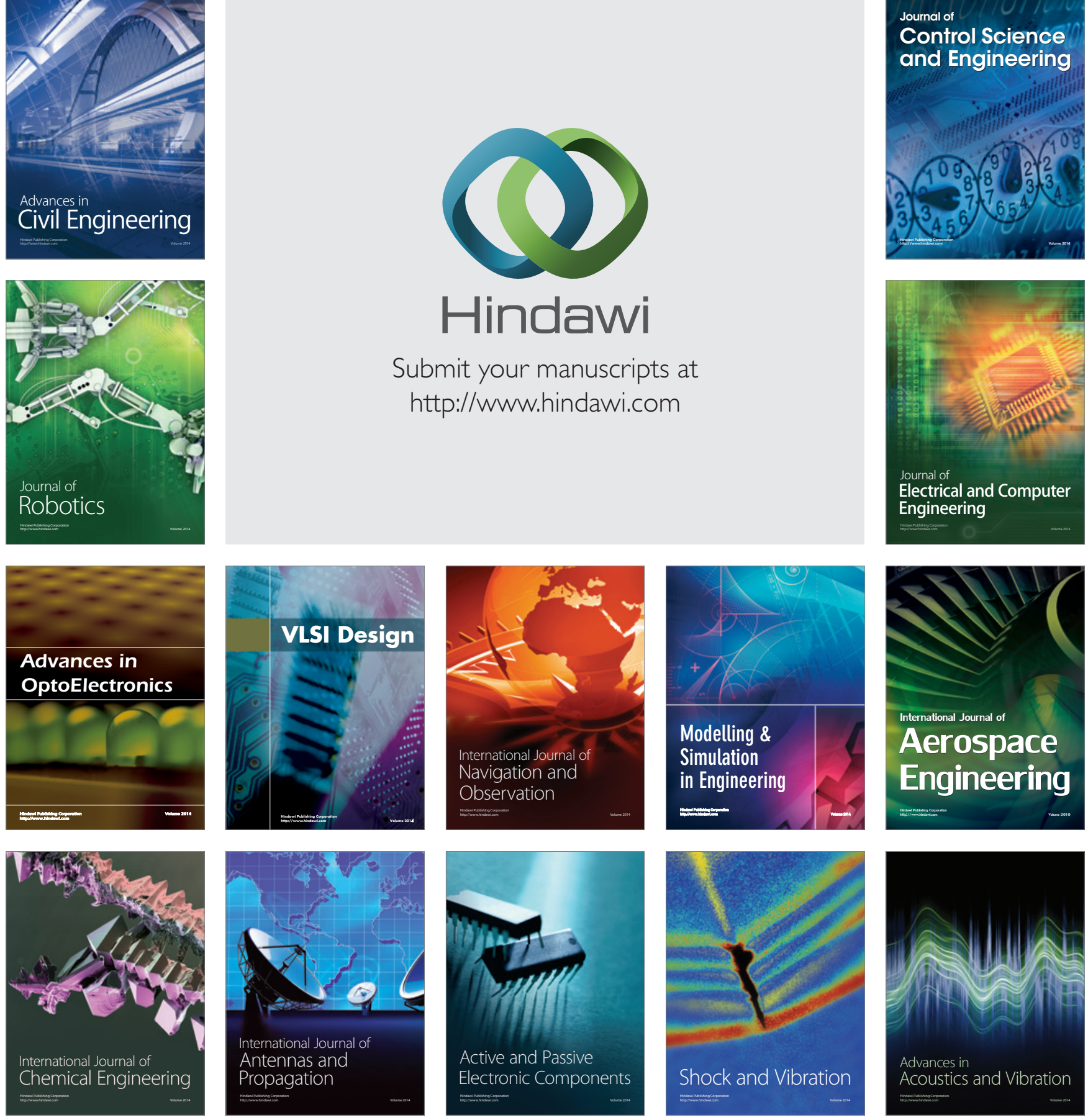